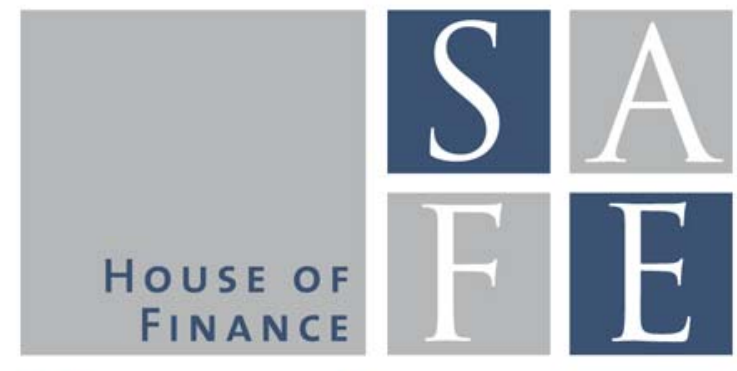

Working PAPER SERIES

Daniel Herbold

\title{
A Repeated Principal-Agent Model with On-the-Job Search
}

SAFE Working Paper No. 64

SAFE I Sustainable Architecture for Finance in Europe

A cooperation of the Center for Financial Studies and Goethe University Frankfurt 


\section{Non-Technical Summary}

This paper studies optimal incentive contracts when workers can actively search for outside offers from other employers. On-the-job search (henceforth OJS) is a common practice in many employment relationships and its incidence has increased substantially in recent decades. The primary reason why employees search for alternative job offers is to get a better job. At the same time, in many industries, employees perform OJS in order to improve their bargaining position in their current employment relationship. This rent-seeking motive of OJS is especially relevant in human-capital intensive industries. At the same time, OJS is costly. Workers need to spend time and effort to locate good job offers. Thus, a worker's productivity in his current job declines, if he spends more resources searching for other jobs. The preceding considerations suggest that OJS has a non-negligible impact on the moral hazard problem that characterizes most employment relationships. OJS affects both the size of the expected surplus created by a relationship, as well as its distribution among employer and worker. Furthermore, since the worker must allocate his attention between work and search, OJS also alters the incentive structure of the relationship.

This paper investigates to what extent firms can mitigate the adverse effects of OJS through the design of the incentive contract. I study a situation in which the worker is supposed to work for the principal but can at the same time search for alternative job offers. He dislikes both working and searching. Yet, he values receiving offers from competing employers, since these either get him a better job or improve his bargaining position within his current employment relationship. By contrast, due to moral hazard, the worker will only work if he is rewarded for good performance.

I show that the optimal incentive contract when the worker can perform OJS features excessive, i.e. inefficiently high bonus payments plus large fixed wage payments. Intuitively, compared to a situation without OJS, bonus payments have an additional advantage when the worker has the ability to look for other jobs. Besides motivating work effort, they also reduce the agent's search activities. Hence, firms will prefer to pay higher bonuses to discourage too much OJS. Furthermore, paying a high fixed wage also prevents the worker from performing too much OJS. If the worker already receives a high level of compensation, he has less reason to improve his bargaining position by sampling attractive outside offers.

Thus, merely accounting for the fact that workers can always search for alternative jobs leads to rich implications regarding the structure of optimal incentive contracts that are highly consistent with the shape of observed compensation contracts. Furthermore, the results shed light on some recent developments in the labor market. In the last twenty to thirty years, the use of performance pay and the level of worker's fixed wages have increased considerably, especially for workers in high-skilled jobs. At the same time, recent decades have also witnessed an increase in firms' demand for general human capital which has arguably improved workers' outside options and hence the returns to OJS. The results from this paper suggest a connection between these two phenomena, as higher returns to OJS raise workers' 
incentives to search for other jobs. In turn, employers optimally address this change in workers' behavior by paying higher bonuses and fixed wages. 


\title{
A Repeated Principal-Agent Model with On-the-Job Search
}

\author{
Daniel Herbold* \\ Goethe University, Frankfurt
}

\begin{abstract}
This paper analyzes how on-the-job search (OJS) by an agent impacts the moral hazard problem in a repeated principal-agent relationship. OJS is found to constitute a source of agency costs because efficient search incentives require that the agent receives all gains from trade. Further, the optimal incentive contract with OJS matches the design of empirically observed compensation contracts more accurately than models that ignore OJS. In particular, the optimal contract entails excessive performance pay plus efficiency wages. Efficiency wages reduce the opportunity costs of work effort and hence serve as a complement to bonuses. Thus, the model offers a novel explanation for the use of efficiency wages. When allowing for renegotiation, the model generates wage and turnover dynamics that are consistent with empirical evidence. I argue that the model contributes to explaining the concomitant rise in the use of performance pay and in competition for high-skill workers during the last three decades.
\end{abstract}

Keywords: Repeated Principal-Agent Model, On-the-Job Search, Moral Hazard, Multitasking, Efficiency Wages.

JEL Classification Numbers: C73; D82; D86; J33; L14

*Address: Goethe-University, Grueneburgplatz 1, D-60323 Frankfurt, e-mail: herbold@econ.uni-frankfurt.de. I thank Ricardo Alonso, Guido Friebel, Susanne Goldlücke, Sergei Guriev, Michael Kosfeld, Matthias Kräkel, Mike Powell, Jean-Charles Rochet, Klaus Schmidt, Heiner Schumacher, Dirk Sliwka and Jörgen Weibull for valuable comments and discussions. Support from the Research Center SAFE, funded by the State of Hessen initiative for research LOEWE is gratefully acknowledged. 


\section{Introduction}

This paper studies how on-the-job search by the agent affects the moral hazard problem and the optimal incentive contract in a repeated principal-agent relationship. On-the-job search (henceforth OJS) is a common practice in many employment relationships and its incidence has increased substantially in recent decades. ${ }^{1}$ The primary reason why employees search for alternative job offers is to get a better job. At the same time, in many industries, employees perform OJS in order to improve their bargaining position in their current employment relationship. Cahuc, Postel-Vinay, and Robin (2006) and Yamaguchi (2010) find that outside offers account for a considerable share of workers' wage increases during the early stages of their careers. This rent-seeking motive of OJS is especially relevant in human-capital intensive industries. At the same time, OJS is costly. Workers need to spend time and cognitive effort to locate good job offers. ${ }^{2}$ Thus, a worker's productivity in his current job will decline, if he spends more resources searching for other jobs. ${ }^{3}$

The preceding considerations suggest that OJS has a non-negligible impact on the moral hazard problem that characterizes most employment relationships. OJS affects both the size of the expected surplus created by the relationship, as well as its distribution among employer and worker. And since the worker must allocate his attention between work and search, OJS also alters the incentive structure of the relationship.

This paper investigates to what extent firms can mitigate the adverse effects of OJS through the design of the incentive contract. I study an infinitely repeated principal-agent relationship in which the agent faces a multitasking problem between work and search effort. While work effort raises the principal's expected revenue, search effort improves the distribution over the agent's outside option that is randomly drawn at the beginning of the subsequent period. OJS therefore raises the agent's continuation payoff by either getting him a better job or by improving his bargaining position vis-à-vis the principal. In equilibrium, there is an endogenous separation threshold such that the agent will leave the principal whenever the draw of his outside option exceeds this threshold. Hence, if there exist more productive job opportunities, OJS is socially valuable and the agent will change jobs on the equilibrium path. I assume that the agent's costs of effort are convex in the sum of work and search effort, implying that the agent faces an effort-substitution problem in the spirit of Holmström and Milgrom (1991).

When the agent's actions are contractible, the principal prefers to implement a positive level of search effort. The intuition is that when search is socially valuable, allowing some OJS raises the agent's utility from the job, thereby relaxing his participation constraint. Under hidden

\footnotetext{
${ }^{1}$ Fallick and Fleischman (2004) document the widespread occurrence of job-to-job transitions in the U.S. labor market, while evidence by Jaeger and Stevens (1999), Neumark, Polsky, and Hansen (1999) and Stewart (2002) indicates that employer-to-employer transitions have increased substantially over time. Further, Stevenson (2009) finds that the rise of the internet has been associated with a substantial increase in online job search of employed workers.

${ }^{2}$ Workers need to spend time searching the internet for job offers, preparing for and going to job interviews, acquiring job-specific skills, and so forth.

${ }^{3}$ Clearly, a worker who searches for alternative jobs during official working hours spends less time working for his employer. But even if a worker searches only during his leisure time, his on-the-job productivity will still suffer, as he will be less recovered when getting back to work.
} 
action, by contrast, the principal can manipulate the agent's behavior only indirectly via the offered compensation contract. Since OJS influences the agent's future continuation payoff, his decision problem is intertemporal, thus rendering the contracting problem dynamic. The benefits of OJS depend on the way, the agent's continuation payoff changes with his outside option. When the agent's participation constraint binds, his continuation payoff varies one-toone with his outside option. In that case, the rent-seeking motive of OJS is maximized. Hence, if the principal receives all gains from trade, the agent has excessive search incentives. It follows that under OJS, the principal faces a tradeoff between efficiency and rent extraction. The firstbest solution requires the complete absence of any rent-seeking incentives, which can only be achieved if the agent receives all gains from trade. Therefore, when the principal maximizes her profits, equilibrium will be inefficient. ${ }^{4}$ This result is striking as the model features no frictions such as limited liability, risk aversion or incomplete contracts that are usually responsible for the existence of agency costs. Hence, the mere possibility to perform OJS constitutes a source of agency costs in repeated principal-agent relationships.

Thus, under OJS, the principal's problem of optimal incentive provision is two-fold: Besides motivating the agent to work, the incentive contract must also curb his OJS activities. In this setting, output-contingent bonus payments serve a dual role. By raising the benefits of work effort, a higher bonus simultaneously increases the opportunity costs of OJS, thereby reducing the agent's search incentives. The principal thus offers higher levels of performance-pay than in the absence of OJS. Further, while the principal never prefers to implement first-best effort incentives, she may benefit from leaving a small employment rent to the agent. Paying such an efficiency wage directly reduces the rent-seeking motive of OJS, thereby raising the agent's work effort incentives. Paying an efficiency wage therefore has the same qualitative effects on the agent's effort incentives as increasing the bonus. However, the magnitudes of these two effects are different. A unit reduction in search effort generated by an increase in the bonus raises work effort by a larger amount than an identical reduction in search effort induced by raising the efficiency wage. Hence, efficiency wages and bonus payments are complements rather than substitutes. At the margin, efficiency wages entail a more favorable rate of substitution between work and search effort than bonus payments. Yet, the payment of efficiency wages must be self-enforcing. I show that the optimal incentive contract features efficiency wages if the implied increase in total surplus exceeds the rent that the principal must give up.

Further, I show that for certain realizations of the agent's outside option, principal and agent have an incentive to renegotiate the efficiency wage upwards. Thus, when allowing for renegotiation, the optimal incentive contract becomes non-stationary with the level of pay increasing with the duration of the relationship and the separation rate decreasing with tenure. Both of these results are well-established empirical regularities (see e.g. Farber (1999) and Topel and Ward (1992)). Existing repeated principal-agent models are typically unable to generate such dynamic patterns.

\footnotetext{
${ }^{4}$ The inefficiency does not even vanish if principal and agent can write long-term contracts that allow them to contract on the agent's outside option. In that case, efficient effort incentives would require the principal to formally agree to surrender all future gains from trade, which cannot be optimal.
} 
I study the robustness of these results in a number extensions. First, I show that when the agent is protected by limited liability, the rent that he receives if he can perform OJS exceeds the "pure" limited-liability rent. Further, when output is unverifiable such that performance bonuses must be supported by a relational contract, efficiency wages become even more valuable. In that case, paying a higher efficiency wage simultaneously raises the maximum discretionary bonus that the principal can credibly promise to pay. Hence, efficiency wages improve the sustainability of high bonus payments in addition to providing valuable effort incentives.

The results of the paper provide a novel explanation for the use of efficiency wages in employment contracts. In the classic shirking model (see e.g. Shapiro and Stiglitz (1984)), efficiency wages motivate workers because their payment is tied to a threat of dismissal in case the agent is caught shirking. In the present paper, employment rents are not coupled with firing threats. Rather, efficiency wages incentivize the agent by reducing the opportunity costs of work effort. Further, in the classic shirking model, the principal can monitor the agent's actions. By contrast, this paper rationalizes the use of efficiency wages in an imperfect monitoring environment where the principal can observe only a noisy measure of the agent's effort choice. ${ }^{5}$ Finally, while the existing literature has identified conditions under which firms prefer to use either efficiency wages or performance pay (see MacLeod and Malcomson (1998)), the results of this paper justify why firms want to use both instruments simultaneously. Thus, the results provide rationalize why firms want to use a combination of different incentive instruments even in the absence of incomplete contracting problems.

The paper's results also suggest a link between two labor market developments that have simultaneously occurred over the last thirty years. The use of performance pay in employment contracts, as well as the level of pay have increased substantially, especially in high-skill jobs. ${ }^{6}$ At the same time, workers' mobility in the labor market has also increased considerably. ${ }^{7}$ The results of this paper suggest that the change in the structure of compensation contracts is at least partly driven by firms reacting to increased competition from outside employers. In particular, to the extent that high-skill workers have better outside options and therefore higher search incentives, the results suggest that high-skill workers should on average face higher-powered incentive schemes than low-skill workers, which is consistent with the empirical evidence (See e.g. Lazear (1998).). Further, while increased labor market mobility has widely been lauded as improving match formation in the labor market, the results in this paper suggest a potential downside to a more mobile workforce embodied by the agency costs created by higher incentives to perform OJS.

The next section relates the paper to the extant literature. Section 3 introduces the model setup. Section 4 characterizes the optimal incentive contract under the restriction that the agent earns no rent from employment. Section 5 analyzes the merits of efficiency wages. Section 6 discusses extensions. Section 7 concludes. All proofs are relegated to the appendix.

\footnotetext{
${ }^{5}$ As argued by Levin (2003), this assumption is in the spirit of the classic agency literature which views informational frictions rather than enforcement problems as the main impediment to efficient contracting.

${ }^{6}$ The next section lists several papers that provide corresponding evidence.

${ }^{7}$ E.g. skill-biased technical change has contributed to an increase in the relative demand and the competition for general human capital. See e.g. Katz and Autor (1999).
} 


\section{Related Literature}

The present paper adds to the large literature that models employment as an ongoing principalagent relationship. This literature studies how the long-term nature of employment relationships influences their terms of trade. Radner (1985) examines how the longevity of trade can help reduce the risk exposure of a risk-averse agent. Further, the vast literature on relational contracts studies how repeated interactions helps parties sustain self-enforcing, implicit incentive contracts when explicit contracts are not feasible (key references include Bull (1987), MacLeod and Malcomson (1989) and Levin (2003). Malcomson (2012) provides a comprehensive survey.). I add to this literature by showing that under OJS, the optimal incentive contract matches several attributes of observed employment contracts more accurately compared to the predictions of most previous work.

Workers' decision to perform OJS has been predominantly studied in search-theoretic models of the labor market. While some papers have focused on how workers' search incentives vary with features of the environment (e.g. Christensen, Lentz, Mortensen, Neumann, and Werwatz (2005), Lentz (2010) and Lise (2013)), others have analyzed how firms can manipulate workers' search incentives by designing appropriate employment contracts (Postel-Vinay and Robin (2004), Holzner (2011) and Lentz (2014)). The latter class of papers studies the shape of optimal long-term wage contracts and whether employers are better off committing to not matching outside offers when their employees can perform costly OJS. However, these papers do not consider the agent's multitasking problem between work and search effort and are therefore agnostic about the impact of OJS on the incentive contract. Furthermore, while these papers assume that the employer can commit to a long-term wage contract, I follow the literature on repeated principal-agent games by assuming that the parties can only write spot contracts. With spot contracts, any rent payment that is supposed to alter the agent's search incentives must be self-enforcing. Hence, this paper adds to the extant literature by studying the interplay between OJS and performance incentives and by providing a strategic foundation of the form of optimal compensation contracts under OJS.

One paper that does study the impact of OJS onto the incentive contract is Moen and Rosen (2013). They show that OJS reduces the effectiveness of incentive contracts when the agent can only be incentivized via deferred compensation. However, they abstract from multitasking between work and search effort and ignore the rent-seeking motive of OJS. Board and Meyer-ter Vehn (2013) analyze the role of OJS in a market equilibrium where firms use relational contracts to incentivize their workers. In their model, OJS is no choice variable. Rather, they study how the market equilibrium changes when not only unemployed, but also employed workers receive job offers from firms with vacancies.

Further, the paper contributes to the literature on optimal incentive contracts under multitasking. The main insight of the seminal contributions by Holmström and Milgrom (1991, 1994) was that the agent's incentives to perform a task depend not only on the direct benefits from performing that task but also on its opportunity costs embodied by the rewards from performing other tasks. I contribute to this literature by showing that when the consequences of 
some of the agent's tasks realize in the future, the principal must take into account the dynamic implications for the agent's decision problem when designing the optimal incentive contract. Baker, Gibbons, and Murphy (2002) and Gibbons (2005) analyze dynamic contracting under hold-up. In their setting, agents face a multitasking problem between productive effort and a rent-seeking activity that improves their bargaining position. In their model, the rent-seeking activity influences the ex-post division of current-period surplus, while in this paper, OJS affects the ex-ante division of the continuation surplus. Therefore, in their model, efficient effort incentives do not require giving the entire surplus to the agent. Instead, the inefficiency is caused by parties' inability to contract ex-ante on the division of surplus. By contrast, the results in this paper show that even complete contracts do not reduce the inefficiency if rent-seeking refers to the expropriation of future surplus.

In another related paper, Giannetti (2011) studies a two-period principal-agent model where in the initial period, the agent must choose between a short- and a long-term strategy. While the long-term strategy generates higher profits for the principal, the short-term strategy raises the agent's outside option in the second period. Akin to the mechanism in this paper, the agent must receive a sufficiently high share of the second-period surplus to be prevented from implementing the action that raises his outside option. However, Giannetti (2011) studies no multitasking problem and assumes that the principal can commit to a two-period contract and thus abstracts from the problem of making the rent payment in the second period self-enforcing.

Finally, a large empirical literature has documented a surge in the use of performance pay in employment contracts as well as a rise in pay levels over the last three decades, especially for workers in the upper end of the income distribution (see e.g. Brown and Heywood (2002), Lazear and Shaw (2007), Lemieux, MacLeod, and Parent (2009) and Frydman and Saks (2010) ). Some studies have argued that this development has likely been caused by improvements in information and measurement technology (e.g. Lemieux, MacLeod, and Parent (2009)), while others view market and governance failure as its key driver (e.g. Bertrand and Mullainathan (2001) and Bebchuk and Fried (2003)) The results in this paper support the view that a shift in employers' demand from firm-specific to more general skills such as managerial talent was a key driver behind this trend. ${ }^{8}$ By raising the value of workers' services for other employers, this surge in demand for general human capital has arguably raised the returns to performing OJS. In a related paper, Bénabou and Tirole (2013) also argue that increased competition for high-ability workers is a critical determinant of the stark increase in the use of performance pay. In their model, competition for talent leads firms to make excessive use of performance pay in order to attract and retain high-skill workers. This creates an inefficiency as workers divert their attention from tasks with a public-good character to those that are more easily measured. While in their model, excessive performance pay is the source of the inefficiency, in this paper, firms use high bonuses to counteract the agent's harmful search activities.

\footnotetext{
${ }^{8}$ Empirical evidence documenting this trend can be found in Katz and Autor (1999), Berman, Bound, and Machin (1998) and Frydman (2007). Murphy and Zabojnik (2004), Frydman (2007) and Lemieux, MacLeod, and Parent (2009) develop formal arguments that relate the increased demand for general skills to higher (performance) pay.
} 


\section{Model}

Setup Consider a principal (she) and an agent (he), both risk-neutral, who can trade over an infinite time horizon with dates indexed by $t=1,2, \ldots$. At the beginning of date $t$, nature draws an outside option $r_{t}$ for the agent from the interval $[\underline{r}, \bar{r}]$. The principal's outside option is deterministic and denoted by $\bar{\pi}$. After both players observe $r_{t}$, the principal makes a contract offer to the agent. The agent's participation decision is denoted $d_{t} \in\{0,1\}$. If the agent accepts the principal's offer $\left(d_{t}=1\right)$, he subsequently exerts work effort $e_{t} \in[0, \bar{e}]$ and search effort $s_{t} \in[0, \bar{s}]$, at private $\operatorname{costs} c\left(e_{t}+s_{t}\right)$, with $c(0)=0, c^{\prime}()>0,. c^{\prime \prime}()>$.0 and $c^{\prime}(\bar{e})=c^{\prime}(\bar{s})=+\infty$. The pair $\left(e_{t}, s_{t}\right)$ is called the agent's effort profile. The principal can neither observe $e_{t}$ nor $s_{t}$.

Work effort generates a stochastic output $y_{t} \in\{\underline{y}, \bar{y}\}$ for the principal. Given $e_{t}$, the probability that $y_{t}=\bar{y}$ is $f\left(e_{t}\right) \in(0,1)$, with $f^{\prime}()>$.0 and $f^{\prime \prime}() \leq$.0 . Output is publicly observable and verifiable to third parties. The expected total surplus created at date $t$ given $\left(e_{t}, s_{t}\right)$ is denoted by $T\left(e_{t}, s_{t}\right) \equiv \mathbb{E}_{y}\left(y_{t} \mid e_{t}\right)-c\left(e_{t}+s_{t}\right)$. For given $s$, the period-surplus-maximizing work effort level is denoted $e^{*}(s)$ with the associated maximum period surplus given by $T^{*}(s) \equiv$ $T\left(e^{*}(s), s\right)$. I assume that $e^{*}(s)$ is unique for every $s$. Total surplus created in any period $t$ is maximized by the pair $\left(e_{t}, s_{t}\right)=\left(e^{*}(0), 0\right)$.

Search effort at date $t$ influences the probability distribution of the agent's outside option at $t+1$. In particular, $r_{t}$ is drawn according to the cumulative distribution function $G\left(r_{t} \mid s_{t-1}\right)$, with $G_{s}(r \mid s) \leq 0$ and $G_{s s}(r \mid s) \geq 0$, where $G_{s}(. \mid$.$) and G_{s s}(. \mid$.$) denote the first- and second-order$ partial derivatives of $G(. \mid$.) with respect to $s$. So at any date $t$, the distribution of the agent's outside option for a given search effort level in the previous period dominates (is dominated by) any distribution associated with a lower (higher) previous-period search effort level in the sense of first-order stochastic dominance. Further, $G(\bar{r} \mid s)=1$ and $G(\underline{r} \mid s)=0$ for all $s$ and $g(r \mid s) \equiv G_{r}(r \mid s)$, where $G_{r}(. \mid$.) denotes the partial derivative of $G(. \mid$.) with respect to $r$. I assume that $G$ is degenerate with $G(r \mid s)=1$ for all $r \in[\underline{r}, \bar{r}]$ if $s=0$, but that it has full support for any $s>0$. That is, in order to receive a job offer, the agent must exert at least a minimal amount of search effort. ${ }^{9}$

If the agent rejects the principal's offer at date $t\left(d_{t}=0\right)$, the game ends $\left(d_{\tau}=0\right.$ for all $\tau>t$ ) and both players receive their current-period outside options in perpetuity. ${ }^{10}$ I impose the condition that there are other jobs in the economy when the agent is more productive:

\section{Assumption A1.}

$$
\bar{r}>T^{*}(0)+\bar{\pi}
$$

\footnotetext{
${ }^{9}$ Assuming that the agent draws a new outside option in every period reflects the assumption that he cannot recall any offers he has rejected in the past.

${ }^{10}$ One could allow principal and agent to meet again in the period after the agent has rejected the principal's offer. In that case, it would be natural to assume that the agent carries the outside option he accepted at date $t$ over to date $t+1$ i.e. $r_{t}=r_{t-1}$ whenever $d_{t-1}=0$. These assumptions would not change any of the paper's results since in equilibrium, the agent will never accept an offer by the principal at some date $\tau$ if he has rejected her offer at some prior date $t<\tau$. Further, in the studied environment, temporary separations off equilibrium do not enhance the set of equilibrium payoffs. Finally, it would be inconsistent to assume that while the agent cannot recall past outside options from alternative employers, the principal is always in the position to make him an offer.
} 
If A1 holds, search effort entails a social benefit. Throughout the analysis, I will recurrently discuss how results change if $\mathrm{A} 1$ is relaxed, i.e. if the studied relationship is the most productive in the economy.

At date $t$, the contract offer by the principal specifies a fixed wage $w_{t}$ and an outputbased bonus $b_{t} \in\left\{\underline{b}_{t}, \bar{b}_{t}\right\}$. The fixed wage $w_{t}$ is paid by the principal conditional on the agent's acceptance decision. After output has realized, the principal pays $\underline{b}_{t}$ if $y_{t}=\underline{y}$ and $\bar{b}_{t}$ if $y_{t}=\bar{y}$. Both components of the compensation contract are court-enforceable. The agent is not protected by limited liability, implying that total compensation $W_{t} \equiv w_{t}+b_{t}$ can be negative. Hence, there is no loss of generality in setting $\underline{b}_{t}=0$ and $\bar{b}_{t}=b_{t}$.

Both players discount future payoffs with the common factor $\delta \in(0,1)$. The expected discounted payoffs for principal and agent at date $t$ are

$$
\begin{gathered}
\pi_{t}=(1-\delta) \mathbb{E}\left[\sum_{\tau=t}^{\infty}\left[d_{\tau}\left(y_{\tau}-W_{\tau}\right)+\left(1-d_{\tau}\right) \bar{\pi}\right]\right], \\
u_{t}=(1-\delta) \mathbb{E}\left[\sum_{\tau=t}^{\infty}\left[d_{\tau}\left(W_{\tau}-c\left(e_{\tau}+s_{\tau}\right)\right)+\left(1-d_{\tau}\right) r_{\tau}\right]\right],
\end{gathered}
$$

respectively. Note that payoffs are expressed in per-period averages. Let $Q_{t}=\pi_{t}+u_{t}$ denote the average total surplus created per period. ${ }^{11}$

Throughout the paper, all payoffs are expressed as per-period averages of the supergame. This is especially important for the interpretation of players' outside options. In particular, every $r \in[\underline{r}, \bar{r}]$ represents the average per-period payoff, the agent can expect to receive if he accepts the job associated with the offer $r$. Hence, taking $[\underline{r}, \bar{r}]$ as given does not imply that the agent stops searching for alternative jobs once he rejects the principal's offer in favor of another offer. ${ }^{12}$

Equilibrium I study perfect public equilibria (henceforth PPE) of the repeated game. Under a PPE, the actions prescribed by players' (public) strategies must constitute a Nash equilibrium at every decision node and for every public history leading to that decision node (Fudenberg, Levine, and Maskin (1994)). ${ }^{13}$ Let $\pi_{t}\left(r_{t}, d_{t}\right)$ and $u_{t}\left(r_{t}, d_{t}\right)$ denote the principal's and the agent's continuation payoffs at date $t$ under some public strategy profile, as functions of $r_{t}$ and $d_{t}$. PPE imposes the following constraints on players' behavior:

\footnotetext{
${ }^{11}$ Thus, $Q_{t}$ does not only contain the surplus, created by principal and agent in periods in which they trade with each other, but also the sum of the payoffs generated by principal and agent individually at dates $t$ with $d_{t}=0$.

${ }^{12}$ The appendix describes a model of a labor market with search frictions populated by a mass of firms that differ with respect to the productivity of the job(s) they offer in which the interval $[\underline{r}, \bar{r}]$ is endogenously determined, but still taken as given by every individual firm.

${ }^{13}$ Restricting attention to public strategies is without loss. The agent does have private information regarding his effort choices. However, since this kind of private information is one-sided, the outcome of any equilibrium in which players use private strategies is also the outcome of an equilibrium where players use public strategies. See Mailath and Samuelson (2006).
} 
Definition 1. A public strategy profile constitutes a Perfect Public Equilibrium if and only if:

For any date $t, d_{t}=1$ if and only if $\pi_{t}\left(r_{t}, 1\right) \geq \bar{\pi}$ and $u_{t}\left(r_{t}, 1\right) \geq r_{t}$.

Conditional on $d_{t}=1$, the agent chooses $\left(e_{t}, s_{t}\right)$ such that:

$$
\left(e_{t}, s_{t}\right) \in \arg \max _{e, s}(1-\delta)\left[\mathbb{E}_{y}\left(W_{t} \mid e\right)-c(e+s)\right]+\delta \int_{\underline{r}}^{\bar{r}} u_{t+1}\left(r, d_{t+1}\right) g\left(r \mid s_{t}\right) d r .
$$

$(P C)$ ensures that players' participation decisions are individually rational. Under A1, $(P C)$ implies that there exists a separation threshold, $\rho^{E Q}$, such that $d_{t}=0$ for any $r_{t}>\rho^{E Q}$. $(I C)$ reflects the hidden action problem. The agent chooses work and search effort optimally, given the offered bonus scheme and given how his continuation payoff changes with $r_{t+1}$. Since the principal makes a take-it-or-leave-it offer to the agent at every date $t$, I focus on PPE that maximize the principal's profits, i.e. I consider the principal's maximization problem subject to $(P C)$ and $(I C)$. In particular, I require that the principal maximizes his profits in any continuation equilibrium. ${ }^{14}$

No Search Note that the model involves no frictions such as risk aversion, limited liability or incomplete contracts that create distortions in standard moral hazard models without search effort. Thus, without the possibility to search on the job $\left(s_{t}=0\right.$ for all $\left.t\right)$, the principal would maximize her profits by setting $b_{t}=\Delta y$ for every $t$, thereby implementing $T^{*}(0)$ and adjusting the fixed wage such that the agent earns no rent from employment.

Symmetric Information Before characterizing optimal incentive contracts with on-thejob search, I consider as a benchmark the case of symmetric information about the agent's effort decisions. In this case, the principal can directly choose the effort profile $\left(e_{t}, s_{t}\right)$ by offering the agent a forcing contract.

Lemma 1. If $\left(e_{t}, s_{t}\right)$ is observable and contractible, then ...

(i) ... the profit-maximizing effort profile $\left(e^{S I}, s^{S I}\right)$ maximizes total surplus.

(ii) ... under assumption A1, there is $\rho^{*}<\bar{r}$ such that if $r_{t}>\rho^{*}, d_{\tau}=0$ for all $\tau \geq t$.

(iii) ... the principal implements a stationary effort profile $\left(e^{S I}, s^{S I}\right)$ at every date $t$ with $d_{t}=1$.

As the principal can dictate the effort profile to the agent, she does not need to respect $(I C)$. Hence, the creation of surplus can be decoupled from its division, implying that the symmetric information solution is not only optimal from the principal's, but also from a social perspective. Further, since the production technology is stationary, the profit-maximizing effort profile and the surplus created in every period in which principal and agent trade is also

\footnotetext{
${ }^{14}$ This restriction is supposed to capture the notion that the principal cannot sell the firm to the agent. It is natural to make such an assumption when studying incentives in an employment relationship.
} 
stationary. Therefore, there is a stationary separation threshold $\rho^{*}$ such that the surplus created under the relationship is not sufficient to satisfy $(P C)$, whenever $r_{t}>\rho^{*}$. Thus, as soon as $r_{t}>\rho^{*}$, the relationship is severed for good.

For a given (non-equilibrium) separation threshold $\rho$, total surplus created under the stationary effort profile $(e, s)$ can be written as:

$$
Q(e, s, \rho)=\phi(\rho, s) T(e, s)+[1-\phi(\rho, s)]\left[\mathbb{E}_{r}(r \mid r>\rho, s)+\bar{\pi}\right], \text { where } \phi(\rho, s)=\frac{1-\delta}{1-\delta G(\rho \mid s)} .
$$

Total surplus is a weighted average of the surplus generated per period in which the relationship is continued and the sum of the payoffs that principal and agent receive individually per period after having separated. The weight attached to the per-period surplus created in either of the two states depends on the probability of separation $G(\rho \mid s)$. The efficient separation threshold, $\rho^{*}$ is determined by $(P C)$. Let $\left(e^{S I}, s^{S I}\right)$ denote the surplus-maximizing effort profile and $Q^{S I}$ the corresponding surplus. Since profit-maximization requires $u\left(r_{t}, 1\right)=r_{t}$ for any $r_{t}$ that satisfies $(P C)$, the efficient separation threshold $\rho^{*}$ is given by

$$
Q^{S I}-\rho^{*}=\bar{\pi}
$$

Notice that $\rho^{*}$ is implicitly defined, because total surplus is itself a function of $\rho^{*}$. Thus, the probability of separation $G\left(\rho^{*} \mid s^{S I}\right)$ is endogenously determined by players' equilibrium behavior. Hence, when $(P C)$ is satisfied, total surplus can be expressed solely in terms of the effort profile, i.e. $Q\left(e, s, \rho^{*}\right)=Q(e, s)$. In particular, any increase in $Q$ raises $\rho^{*}$ by an identical amount which in turn increases $Q$ even further. The appendix proves that the implied multiplier effect amounts to $\frac{1}{1-\delta G\left(\rho^{*} \mid s\right)}$. That is, if, holding $\rho^{*}$ constant, total surplus changes by $\Delta Q$, then the aggregate effect on total surplus is $\frac{\Delta Q}{1-\delta G\left(\rho^{*} \mid s\right)}$. Thus, under symmetric information, the principal chooses $(e, s)$ as to maximize $Q(e, s)$ subject to $(P C)$. Let $Q_{e}\left(Q_{s}\right)$ denote the partial derivative of the total surplus function with respect to $e(s)$. The profit-maximizing effort profile under symmetric information is characterized by $Q_{e}=Q_{s}=0$, implying the following two conditions: ${ }^{15}$

$$
\begin{gathered}
f^{\prime}(e) \Delta y=c^{\prime}(e+s), \\
\frac{\delta G_{s}\left(\rho^{*} \mid s\right)}{1-\delta G\left(\rho^{*} \mid s\right)}\left[T(e, s)-\mathbb{E}_{r}\left(r \mid r>\rho^{*}, s\right)-\bar{\pi}\right]+\frac{\delta}{1-\delta} \int_{\rho^{*}}^{\bar{r}} r g_{s}(r \mid s) d r=c^{\prime}(e+s) .
\end{gathered}
$$

The principal equates the marginal benefits of the two effort dimensions in order to maximize total surplus. ${ }^{16}$ These benefits are given by the left-hand sides (LHS) of $\left(S I C_{e}\right)$ and $\left(S I C_{s}\right)$, respectively. Denote the optimal value of $e$ as a function of $s$ as defined by $\left(S I C_{e}\right)$ by $\widehat{e}^{S I}(s)$ and let $\widehat{s}^{S I}(e)$ conversely denote the optimal value of $e$ as a function of $s$ as defined by $\left(S I C_{s}\right)$. The efficient effort profile $\left(e^{S I}, s^{S I}\right)$ is given by the intersection of these two functions. In general, $s^{S I}$

\footnotetext{
${ }^{15}$ Since $\frac{1}{1-\delta G(\rho \mid s)}>0$, the multiplier drops when forming the problem's first-order conditions.

${ }^{16}$ The second-order sufficient conditions for $\left(S I C_{e}\right)$ and $\left(S I C_{s}\right)$ to represent the problem's unique global maximum can fail only in very special cases. The appendix provides sufficient condition that rule out such cases. Generally, equations $\left(S I C_{e}\right)$ and $\left(S I C_{s}\right)$ represent the problem's unique global maximum if $c($.$) or G(. \mid$.) or both are sufficiently convex.
} 
is positive, because under A1 search is socially valuable. ${ }^{17}$ Intuitively, the principal can benefit from the social value of search because a positive level of search effort improves the agent's future job prospects and therefore increases his payoff from the employment relationship. This allows the principal to reduce the fixed payment necessary to induce the agent to participate and hence raise her profits. So in general, under A1, $e^{S I}<e^{*}(0)$, implying that under the efficient allocation, $T\left(e^{S I}, s^{S I}\right)<T^{*}(0)$. By contrast, if A1 does not hold, search has no social value. In that case, $s^{S I}=0, e^{S I}=\widehat{e}^{S I}(0)=e^{*}(0)$ and $\rho^{*} \geq \bar{r}$ so that the relationship will never be terminated and $Q^{S I}=T^{*}(0)$.

\section{Optimal Incentive Provision}

Suppose now that the agent's effort choices cannot be observed by the principal. In this case, the agent chooses $\left(e_{t}, s_{t}\right)$ according to $(I C)$. Work and search effort are (perfect) substitutes in the agent's costs function. His optimal choice of $e_{t}$ therefore depends on the choice of $s_{t}$ and vice versa. Holmström and Milgrom (1991) were the first to study optimal incentive provision in a setting where an agent engages in multiple tasks. One of their key insights was that in such an environment, the agent's incentives to execute a given task depend not only on the direct benefits from performing the task, but also on its opportunity costs, which are given by the benefits of performing other tasks that compete for the agent's productive resources. To identify the agent's benefits from work and search effort, consider the first-order conditions of his problem at some date $t$ :

$$
\begin{gathered}
f^{\prime}\left(e_{t}\right) b_{t}=c^{\prime}\left(e_{t}+s_{t}\right), \\
\frac{\delta}{1-\delta} \int_{\underline{r}}^{\bar{r}} u_{t+1}\left(r, d_{t+1}\right) g_{s}(r \mid s) d r=c^{\prime}\left(e_{t}+s_{t}\right) .
\end{gathered}
$$

The LHS of $\left(I C_{e}\right)$ and $\left(I C_{s}\right)$ represent the marginal benefits of work and search effort respectively. As the marginal costs of work and search effort are identical for any $\left(e_{t}, s_{t}\right)$, the agent chooses $\left(e_{t}, s_{t}\right)$ as to equate these benefits. ${ }^{18}$ As in a model with one-dimensional effort, a larger performance reward $b_{t}$ raises the benefits from work effort. But because the agent faces an effort-substitution problem, a larger $b_{t}$ simultaneously increases the opportunity costs of search effort. Thus, the bonus scheme serves a dual role, influencing the incentives to exert both work and search effort. Denoting the agent's optimal decision by $\left(e_{t}^{A}, s_{t}^{A}\right)$, we have:

$$
\frac{\partial e_{t}^{A}}{\partial b_{t}}>0, \frac{\partial s_{t}^{A}}{\partial b_{t}} \leq 0 \text { and } \frac{\partial e_{t}^{A}+s_{t}^{A}}{\partial b_{t}}>0
$$

The benefits from search effort by contrast are given by the marginal increase in the continuation payoff the agent expects to receive from next period onwards. More search effort at $t$ shifts the distribution of the outside option he will draw at $t+1$ to the right. But how precisely this shift affects the agent's effort incentives depends on how his continuation payoff varies with his

\footnotetext{
${ }^{17}$ The requirement for $s^{S I}>0$ is that the marginal benefits of $s$ at $\left(e^{*}(0), 0\right)$ must be larger than $c^{\prime}\left(e^{*}(0)\right)$.

${ }^{18}$ The assumptions on $f(),. c($.$) and G(. \mid$.$) ensure that I C_{e}$ and $I C_{s}$ represent the agent's problem's unique global maximum.
} 
outside option which in turn depends on the strategy profile that is played. Clearly, the agent's payoff varies one-to-one with $r_{t+1}$ for any $t+1$ with $d_{t+1}=0$. But, for all $t+1$ for which $(P C)$ holds, how the agent's payoff varies with $r_{t+1}$ depends on how the principal adjusts her offer to the realization of $r_{t+1}$. As a benchmark, I begin with the case in which $u\left(r_{t+1}, d_{t+1}\right)=r_{t+1}$ for any $t+1$ with $d_{t+1}=1$.

\subsection{Constrained Second Best}

$\left(I C_{s}\right)$ indicates that it is expectations about future payoffs that determine the agent's search incentives in a given period. Hence, the principal has a myopic incentive to pay the agent just his outside option, whenever $r_{t}$ is such that $d_{t}=1$. However, if he did this, the agent would expect to receive $r_{\tau}$ at any future date $\tau>t$. He will only believe that $u_{t+1}(r, 1)>r$ for some $r$ if the principal has sufficient incentives to indeed pay $u_{t+1}(r, 1)>r$ when called upon to do so. The conditions under which the payment of such an employment rent is self-enforcing will be studied in the next section. In this section, I study PPE in which the agent earns no rent from employment. This case serves as a natural starting point for the analysis since such PPE always exists. To see this, suppose that the agent believes that $u_{t+1}(r, 1)=r$ for any $r \in[\underline{r}, \bar{r}]$. Taking these beliefs as given, the principal cannot benefit from paying the agent more than his outside option. Hence, she will set $u_{t+1}(r, 1)=r$ for any $r$ with $d_{t+1}=1$, thus fulfilling the agent's expectations. Formally, I impose the following assumption throughout this section:

Assumption A2. At any date t, the agent expects that the principal will make his participation constraint binding at any future date $\tau>t$ with $d_{\tau}=1$, i.e. he expects to receive $u_{\tau}\left(d_{\tau}, r\right)=r$ whenever $d_{\tau}=1$.

I emphasize that A2 restricts only players' beliefs, but not their strategies! In particular, it restricts attention to PPE under which the agent earns no rent from employment, but it does not create artificial equilibria that would not exist in its absence. I call the profit-maximizing incentive contract offered by the principal under A2 the constrained second best solution. Under $\mathrm{A} 2,\left(I C_{s}\right)$ becomes:

$$
\frac{\delta}{1-\delta} \int_{\underline{r}}^{\bar{r}} r g_{s}\left(r \mid s_{t}\right)=c^{\prime}\left(e_{t}+s_{t}\right) .
$$

In the appendix, I prove that attention can be restricted to stationary bonus schemes that implement stationary effort profiles $(e, s) .{ }^{19}$ With stationary effort levels, the termination threshold will be stationary as well.

Under A2, the principal can influence the agent's behavior solely via the bonus scheme. Let $\Xi \equiv\left\{(e, s) \mid(e, s)\right.$ satisfies $\left(I C_{e}\right)$ and $\left(I C_{s}^{\prime}\right)$ for $\left.b \in \mathbb{R}\right\}$ denote the set of effort profiles $(e, s)$ that the principal can implement by varying the bonus scheme if assumption A2 holds. Further, let $\widehat{e}^{A}(s)\left(\widehat{s}^{A}(e)\right)$ denote the agent's optimal choice of $e(s)$ as a function of $s(e)$, as defined by $\left(I C_{e}\right),\left(\left(I C_{s}^{\prime}\right)\right)$. The optimal effort decision by the agent is given by the intersection of these

\footnotetext{
${ }^{19}$ Intuitively, since the production technology and the agent's decision problem are stationary, the principal cannot benefit from implementing a non-stationary effort profile. The corresponding proof is similar to the one in Levin (2003).
} 
two functions and $\Xi$ characterizes the envelope of all points of intersections for different bonus schemes. A2, $\left(I C_{e}\right)$ and $\left(S I C_{e}\right)$ imply:

$$
\widehat{e}^{A}(s)\left\{\begin{array}{l}
<\widehat{e}^{S I}(s), \text { if } b<\Delta y \\
=\widehat{e}^{S I}(s), \text { if } b=\Delta y \\
>\widehat{e}^{S I}(s), \text { if } b>\Delta y
\end{array}\right.
$$

Thus, the principal can fully align the agent's preferences regarding the choice of $e$ by setting $b=\Delta y$. By contrast, in the appendix, it is shown that the LHS of $\left(S I C_{s}\right)$ is strictly smaller than the LHS of $\left(I C_{s}^{\prime}\right)$. Hence $\widehat{s}^{A}(e)>\widehat{s}^{S I}(e)$ for any $e$, i.e. the principal can never fully align the agent's interests regarding the choice of $s$. The reason is that under A2, search determines not only the size of the current-period surplus, but also the (expected) division of surplus created in future periods. In other words, the agent's incentives to search are partly reflecting a rent-seeking motive. Since rent-seeking search effort is socially wasteful, the agent's private search benefits are strictly higher than the social ones. The principal can curb the agent's search incentives by raising $b$, which increases the opportunity costs of search effort. However, this increase is associated with a potentially undesirable rise in work effort. The next result readily follows:

Proposition 1. Under A2, there is no $b$ that implements the efficient effort profile, i.e. $\left(e^{S I}, s^{S I}\right) \notin \Xi$.

Under A2, the principal has only one instrument (the bonus) with which she must incentivize two actions by the agent. Therefore, she is unable to implement the efficient effort profile. In particular, her maximization problem is as follows:

$$
\begin{gathered}
\max _{b} Q(e, s)-u(r, d) \\
\text { for all } r \in[\underline{r}, \bar{r}] \text {, subject to } \\
(P C),\left(I C_{e}\right) \text { and }\left(I C_{s}^{\prime}\right) .
\end{gathered}
$$

Let $b^{c S B}$ denote the solution to this problem and let $\left(e^{c S B}, s^{c S B}\right)$ denote the induced effort profile, creating surplus $Q^{c S B}$. As discussed above, under $\left(I C_{s}^{\prime}\right)$, the principal will never leave a rent to the agent. Hence $u(r, 1)=r$ for all $r$ for which $d=1$. $(P C)$ then determines the range of outside options for which the principal offers a contract to the agent. Let $\rho^{c S B}$ denote the equilibrium separation threshold under the constrained second-best solution. Since $(e, s)$ and $Q(e, s)$ are stationary, $(P C)$ defines the equilibrium separation threshold just as under the symmetric information case by

$$
Q^{c S B}-\rho^{c S B}=\bar{\pi}
$$

By Proposition 1, $Q^{c S B}<Q^{S I}$, implying $\rho^{c S B}<\rho^{*}$. Hence, for any $r \in\left(\rho^{c S B}, \rho^{*}\right]$, the relationship is severed under hidden action, but continued under the efficient allocation. If $\underline{r} \in\left(\rho^{c S B}, \rho^{*}\right]$, the distortion precludes trade between principal and agent altogether. In light 
of Proposition 1, one might conjecture that under the constrained second-best solution, the principal will at least align the agent's preferences regarding the choice of $e$. However, as the next result shows, this is not the case:

Lemma 2. Under A2, the profit-maximizing contract involves $b^{c S B}>\Delta y$.

To see why lemma 2 is true, consider the first-order condition of the principal's maximization problem:

$$
Q_{e} \frac{\partial e^{A}}{\partial b}+Q_{s} \frac{\partial s^{A}}{\partial b}=0
$$

By $\left(I C_{e}\right), Q_{e}=0$ at $b=\Delta y$. But since $\widehat{s}^{A}(e)>\widehat{s}^{S I}(e), Q_{s}<0$ for any $\left(e^{A}, s^{A}\right)$. Hence, at $b=\Delta y$, the principal prefers to raise $b$, because it reduces the loss from excessive search activities, whereas the costs associated with an additional increase of work effort are of second order. Profits are maximized when the benefits of a further reduction in $s$ induced by a marginal increase in $b\left(Q_{s} \frac{\partial s^{A}}{\partial b}\right)$ are just offset by the additional costs implied by the corresponding increase in $e\left(-Q_{e} \frac{\partial e^{A}}{\partial b}\right)$. Hence, the constrained second-best solution is characterized by:

$$
-Q_{e} \frac{\partial e^{A}}{\partial b}=Q_{s} \frac{\partial s^{A}}{\partial b}>0, \text { with } Q_{e}<0 \text { and } Q_{s}<0 .^{20}
$$

Thus, under the constrained second-best solution, the agent works and searches too much. In particular, by Lemma $2, e^{c S B}+s^{c S B}>e^{S I}+s^{S I}$.

Next, suppose that A1 does not hold such that there are no social benefits from search. However, when A2 continues to hold, the rent-seeking motive of OJS is still present. Therefore, $s=0$ can only be achieved by a very high level of $b$ which simultaneously induces an inefficiently high level of work effort. Hence, $s^{c S B}$ will in general be positive, even though it has no social value whatsoever. In fact, the implied distortion may even lead to $\rho^{c S B}<\bar{r}$, while under symmetric information, the relationship is never terminated if A1 does not hold.

\footnotetext{
${ }^{20}$ The appendix proves that the second-order sufficient condition for the first-order condition to constitute the problem's unique maximum is satisfied.
} 


\section{$5 \quad$ Efficiency Wages}

As indicated by the results from the previous section, raising total surplus above $Q^{c S B}$ requires directly manipulating the agent's search incentives. When A2 is dropped, the principal can potentially influence how $u_{t+1}$ changes with $r_{t+1}$. To see this, rewrite $\left(I C_{s}\right)$ as follows:

$$
\frac{\delta}{1-\delta} \int_{\underline{r}}^{\rho^{*}} u_{t+1}(r, 1) g_{s}\left(r \mid s_{t}\right)+\frac{\delta}{1-\delta} \int_{\rho^{*}}^{\bar{r}} r g_{s}\left(r \mid s_{t}\right)=c^{\prime}\left(e_{t}+s_{t}\right) \text {. }
$$

The first part of the LHS of this expression displays the component of the agent's search benefits that the principal can control. Recall that the direct effect of more search effort is a transfer of probability mass from any realization of $r$ to larger realizations. Hence, search incentives are lower, the smaller the attractiveness of high relative to low outside options. $(P C)$ bars the principal from reducing the agent's continuation payoff $u_{t+1}(r, 1)$ below $r$. However, she can make search less tempting by raising the agent's continuation payoff for low realizations of $r$ above $r$, while keeping his continuation payoff for high realizations at $r$. That is, directly reducing search incentives requires the principal to admit a rent to the agent. ${ }^{21}$

Self-Enforcing Rent Payments Reducing the agent's search incentives can work only if the agent is confident that the principal will pay any rent prescribed by the strategy profile. But whenever a strategy profile stipulates paying $u_{t+1}(r, 1)=u>r$, the principal has a myopic incentive to deviate and withhold the rent. To make the payment of $u-r$ self-enforcing, the principal must suffer negative consequences if she withholds it and the costs associated with these consequences must exceed the value of the rent. Thus, whether paying a given rent is self-enforcing depends on the agent's reaction to the principal withholding the rent. I analyze strategies under which in response to a deviation by the principal, the agent's beliefs about continuation play switch to those given by A2. Under such a strategy, continuation play following a deviation by the principal is characterized by the constrained second-best solution. Such a reaction by the agent maximizes the principal's costs of refraining from paying a promised rent and hence constitutes an optimal punishment in the sense of Abreu, Pearce, and Stacchetti (1990). ${ }^{22}$

Efficient Effort Incentives To possess efficient effort incentives, the agent must enjoy the full social benefits and bear the full social costs of his search activities. As the next result shows, this can only be achieved if he gets the entire rent from trade with the principal.

Proposition 2. Under hidden action, $\left(e^{S I}, s^{S I}\right)$ can be implemented only if the agent earns $T(e, s)-\bar{\pi}$ per period in which $d_{t}=1$ or, equivalently, if $u_{t+1}\left(r_{t+1}, 1\right)=Q(e, s)-\bar{\pi}$ for any $r_{t+1} \leq \rho^{*}$.

\footnotetext{
${ }^{21}$ Conditional on $\left(e_{t}, s_{t}\right), b_{t}$ and the continuation payoffs the agent expects to receive, admitting the agent a payoff of $u \geq r_{t}$ is achieved by paying a fixed wage of $w_{t}=\frac{u}{1-\delta}+f\left(e_{t}\right) b_{t}+c\left(e_{t}+s_{t}\right)-\frac{\mathbb{E}\left(u_{t+1}\right)}{1-\delta}$.

${ }^{22}$ In that sense, such strategies maximize the scope for PPE in which efficiency wages are paid.
} 
If the agent gets the entire rent from employment, his payoff at any date $t$ with $d_{t}=1$ does not depend on $r_{t}$. Hence, he is not tempted to search in order to raise his continuation payoff when trade is continued. Further, his benefits from continuing trade with the principal are equal to the corresponding social benefits, ensuring that he implements the efficient separation threshold $\rho^{*}$. When pocketing all gains from trade, the agent enjoys a rent of $\rho^{*}-r_{t}$ which is strictly positive for all $d_{t}=1$ unless $r_{t}$ is just equal to $\rho^{*}$. Thus, efficient search incentives require that the principal pays the agent an efficiency wage. However, in contrast to the classic shirking model (e.g. Shapiro and Stiglitz (1984)), the function of the efficiency wage in this model is not merely to motivate the agent to exert effort, but to prevent excessive on-the-job search. Efficiency wages serve as a complement rather than as a substitute for bonus payments.

While efficiency wages raise total surplus, their payment is costly for the principal. In fact, maximizing total surplus calls for the principal to give up all gains from trade, in which case she receives just her outside option $\bar{\pi}$. Hence, under OJS, the principal will never prefer to implement efficient effort incentives! Further, the next section shows that in general, it is not even possible to implement efficient effort incentives. These results show that the mere possibility to conduct OJS alone constitutes a source of agency costs.

\subsection{Profit-Maximizing Efficiency Wages}

Although the principal does not benefit from implementing efficient effort incentives, she may benefit from leaving the agent a rent for some subset $\left[\underline{r}, r_{0}\right) \subset[\underline{r}, \bar{r}]$, where $r_{0}<\rho^{*}$ represents an efficiency wage threshold. In this section, I analyze strategies by the principal that imply the following continuation payoff for the agent at date $t$ :

$$
u_{t}(r, 1)=\left\{\begin{aligned}
r_{0}, & \text { if } r \leq r_{0} \\
r, & \text { if } r>r_{0}
\end{aligned}\right.
$$

Such a strategy reduces the agent's search incentives, thereby raising total surplus, while allowing the principal to keep a positive share of it. Under this strategy, the agent's search effort incentive compatibility constraint becomes:

$$
\frac{\delta}{1-\delta}\left[G_{s}\left(r_{0} \mid s_{t}\right) r_{0}+\int_{r_{0}}^{\bar{r}} r g_{s}\left(r \mid s_{t}\right)\right]=c^{\prime}\left(e_{t}+s_{t}\right) .
$$

Since $G_{s}\left(r \mid s_{t}\right)<0$ for any $r$, the LHS of $\left(I C_{s}^{\prime \prime}\right)$ is decreasing in $r_{0}$. Together with $\left(I C_{e}\right)$, we have

$$
\frac{\partial e^{A}}{\partial r_{0}} \geq 0, \frac{\partial s^{A}}{\partial r_{0}}<0 \text { and } \frac{\partial e^{A}+s^{A}}{\partial r_{0}}<0 .
$$

A larger efficiency wage threshold $r_{0}$ lowers the agent's benefits from exerting search effort, thereby reducing his optimal search effort level, but raising his optimal work effort level. Qualitatively, these effects are identical to those of the bonus payment. Yet, by (1) and (4), the marginal rates of substitution between work and search effort differ across the two incentive 
instruments:

$$
\frac{\partial e^{A} / \partial b}{\left|\partial s^{A} / \partial b\right|}>1>\frac{\partial e^{A} / \partial r_{0}}{\left|\partial s^{A} / \partial r_{0}\right|}
$$

A one-unit reduction in search effort, induced by a higher bonus payment leads to a larger increase in work effort than an identical reduction of $s$ obtained by an increase in the efficiency wage. It is this disparity in the tradeoffs between raising $e$ and lowering $s$ that make efficiency wages socially valuable. To see this, suppose that the principal takes $r_{0} \in\left[\underline{r}, \rho^{*}\right)$ as given and that she maximizes total surplus subject to $(P C),\left(I C_{e}\right)$ and $\left(I C_{s}^{\prime \prime}\right)$. Let $b\left(r_{0}\right)$ denote the outcome of this problem and let $Q\left(r_{0}\right)$ denote the corresponding total surplus. Because $r_{0}<\rho^{*}$, the agent's private benefits from search are still larger than the corresponding social benefits. Thus, for any $r_{0} \in\left[\underline{r}, \rho^{*}\right), b\left(r_{0}\right)$ is characterized by the first-order condition:

$$
-Q_{e} \frac{\partial e^{A}}{\partial b}=Q_{s} \frac{\partial s^{A}}{\partial b}, \text { with } Q_{e}<0 \text { and } Q_{s}<0
$$

Hence, for any efficiency wage threshold below $\rho^{*}$, the costs of raising $e$ and the benefits of lowering $s$ at the profit-maximizing bonus payment are strictly positive, implying the following result:

Lemma 3. For any $r_{0}<\rho^{*}, Q\left(r_{0}\right)<Q^{S I}$ and $b\left(r_{0}\right)>\Delta y$.

Since the principal never wants to implement efficient effort incentives, Lemma 8 implies that the optimal incentive contract will always feature excessive performance pay. Next, consider a marginal increase in $r_{0}$ at $b=b\left(r_{0}\right)$. (6) and (7) imply

$$
\left[Q_{e} \frac{\partial e^{A}}{\partial r_{0}}+Q_{s} \frac{\partial s^{A}}{\partial r_{0}}\right]_{b=b\left(r_{0}\right)}>0 .
$$

Thus, for any $r_{0} \in\left[\underline{r}, \rho^{*}\right)$ at which $b$ is chosen to maximize profits, raising the efficiency wage increases total surplus, i.e. $Q^{\prime}\left(r_{0}\right)>0$ for any $r_{0} \in\left[\underline{r}, \rho^{*}\right)$. Intuitively, given $Q_{e}<0$ and $Q_{s}<0$, at $b\left(r_{0}\right)$, an additional increase in $b$ would raise $e$ by too much relative to the corresponding decrease in $s$. But, by (6), the increase in $e$ relative to the implied reduction in $s$ associated with a marginal increase in $r_{0}$ at $b\left(r_{0}\right)$ is smaller than the corresponding relative increase of $e$ induced by raising $b$. In other words, at the margin, increasing the efficiency wage entails a more favorable tradeoff between raising $e$ and lowering $s$ than increasing the bonus payment. Hence, increasing $r_{0}$ raises total surplus.

Self-Enforcing Efficiency Wages In a PPE, any rent payment that is to influence the agent's behavior must be self-enforcing. While $Q^{\prime}\left(r_{0}\right)>0$, a higher efficiency wage also raises the principal's temptation to withhold the promised rent. Given the agent's reaction to such a deviation, the payment of the efficiency wage $r_{0}$ is self-enforcing if and only if

$$
Q\left(r_{0}\right)-r_{0} \geq Q^{c S B}-r, \forall r \in\left[\underline{r}, r_{0}\right)
$$


As this condition is most stringent for $r=\underline{r}$, it holds if and only if the following enforcement constraint holds:

$$
Q\left(r_{0}\right)-r_{0} \geq Q^{c S B}-\underline{r} \Leftrightarrow Q\left(r_{0}\right)-Q^{c S B} \geq r_{0}-\underline{r} .
$$

An efficiency wage is self-enforcing if and only if the decrease in surplus induced by withholding the implied rent exceeds the maximum possible reduction in the wage bill. $(E C)$ readily implies the following result.

Lemma 4. PPE that maximize total surplus exist if and only if $Q^{c S B}$ is sufficiently low such that under A2, no relationship will be formed, i.e. $Q^{c S B}-\underline{r} \leq \bar{\pi}$.

Under A2, all gains from trade are pocketed by the principal, but by Proposition 2, totalsurplus maximization requires that the principal gives up all gains from trade. Hence, whenever there are gains from trade under A2, the provision of efficient effort incentives cannot be selfenforcing. Efficient effort incentives can only be provided if the rent-seeking motive under the constrained second-best solution implies agency costs that are so high such that no trade will occur for any $r \in[\underline{r}, \bar{r}]$. By contrast, if $Q^{c S B}>\bar{\pi}+\underline{r}$, all PPE is inefficient! Thus, not only does the option to perform OJS create a tradeoff between efficiency and rent extraction, this tradeoff also implies that in general there exists no PPE that maximizes total surplus.

Existence To derive the existence condition for PPE in which the principal pays an efficiency wage $\left(r_{0}>\underline{r}\right)$, note that a marginal increase in $r_{0}$ raises the principal's costs by exactly one unit. Further, as proven in the appendix, $Q\left(r_{0}\right)$ is a concave function, thus implying the following result:

Proposition 3. PPE in which the principal pays an efficiency wage $\left(r_{0}>\underline{r}\right)$ exist if and only if:

$$
Q^{\prime}\left(r_{0}=\underline{r}\right)=\left[Q_{e} \frac{\partial e^{A}}{\partial r_{0}}+Q_{s} \frac{\partial s^{A}}{\partial r_{0}}\right]_{\left.\left(b, r_{0}\right)=\left(b^{c S B}\right), \underline{r}\right)} \geq 1
$$

Because $Q\left(r_{0}\right)$ is concave, if ( $E W$ ) fails, no increase in surplus induced by a higher efficiency wage can outweigh the coincidental rise in the principal's deviation temptation. By contrast, if $(E W)$ holds, the gain in surplus exceeds the increase in the wage bill for at least some $r_{0}$ slightly above $\underline{r}$. Proposition 3 is illustrated in panel (a) of figure 1. Concavity of $Q\left(r_{0}\right)$ further implies that if $(E W)$ holds, every $r_{0} \in\left[\bar{r}, r_{0}^{\max }\right]$ can be implemented as an efficiency wage in some PPE, where $r_{0}^{\max }$ is defined as the efficiency wage at which $(E C)$ binds. This interval is the larger, the greater the friction and hence the lower the principal's profits under the constrained second-best solution. This relationship is illustrated in figure 2 .

Comparative Statics By $(E W)$, efficiency-wage PPE are more likely to exist, the larger the increase in surplus induced by a marginal increase in the efficiency wage at $r_{0}=\underline{r}$. As for the bonus, a higher efficiency wage raises $e$ while lowering $s$. But by (6), raising the efficiency wage entails a different marginal rate of substitution between $e$ and $s$ compared to raising the bonus. In other words, the more complementary efficiency wage and bonus payments are, the 
more likely the optimal incentive contract will feature the payment of an efficiency wage. $Q^{\prime}(\underline{r})$ is also larger, the greater the rent-seeking motive of OJS under the constrained second-best. Intuitively, the greater the rent-seeking motive, the more excessively the agent will search under the constrained second-best solution, which leads to a higher level of $\left|Q_{s}\right|$ and hence $\left|Q_{e}\right|$ at $b^{c S B}$. Then, by (6) and (7) a given degree of complementarity between efficiency wage and bonuses, translates into a greater difference in marginal profits and hence into a larger slope of $Q\left(r_{0}\right)$ at $r_{0}=\underline{r}$.

Furthermore, as implied by the next result, paying an efficiency wage may even be a necessary condition for an employment relationship to form in the first place.

Lemma 5. If $Q^{c S B}-\bar{r}<\bar{\pi}$ and $\rho^{*} \geq \underline{r}$ (or equivalently, $\underline{r} \in\left(\rho^{c S B}, \rho^{*}\right]$ ), a PPE with $d_{t}=1$ for some $r_{t} \in[\underline{r}, \bar{r}]$ exists if and only if $r_{0}>\underline{r}$.

Lemma 5 refers to employment relationships for which the inefficiency created under A2 precludes trade altogether, even though under symmetric information, $d_{t}=1$ is efficient for some nonempty interval $\left[\underline{r}, \rho^{*}\right]$. As illustrated in figure 3 , in this case, a relationship will form if and only if a sufficiently large efficiency wage is paid.

Finally, consider the case in which A1 does not hold. In this case, $Q(\bar{r})-\bar{r} \geq \bar{\pi}$, yet $r_{0}=\bar{r}$ need not be self-enforcing. However, if $r_{0}<\bar{r}$, the agent will exert a positive level of search effort, thereby creating an inefficiency, because search has no social value. As a result, total surplus generated in equilibrium may be smaller than $\bar{\pi}+\bar{r}$ implying that the relationship will be terminated on the equilibrium path even though it is the most productive relationship in the economy.

\subsection{Equilibrium Selection}

When $(E W)$ holds, there exists a continuum of efficiency-wage equilibria, namely one for each $r_{0} \in\left[\underline{r}, r_{0}^{\max }\right]$. This section examines which of these PPE principal and agent are most likely to coordinate on. To this purpose, I assume that the principal proposes an implicit agreement, characterized by $r_{0}$, in the initial period $t=1$ before the date- 1 compensation contract is offered. In particular, the principal chooses this offer as to maximize her supergame profits. This proposal coordinates the players' actions and beliefs in the subsequently played supergame. Let $r_{0}^{*}$ denote the efficiency wage threshold that maximizes the principal's profits.

In what follows, I show that $r_{0}^{*}$ depends on the realization of the agent's outside option in the initial period, $r_{1}$. To see this, note that the principal's objective function in the initial period is given by $\max \left\{Q\left(r_{0}\right)-u\left(r_{1}, 1\right), \bar{\pi}\right\}$. Since any compensation contract in the initial period must satisfy $(E C)$, the principal's wage costs at $t=1$ under some efficiency wage $r_{0}$ are given by $\max \left\{r_{0}, r_{1}\right\}$. Hence, the problem of maximizing the principal's supergame profits is given by

$$
\max _{r_{0}}\left\{\left[Q\left(r_{0}\right)-\max \left\{r_{0}, r_{1}\right\}\right], \bar{\pi}\right\}, \text { s.t. }(P C),\left(I C_{e}\right),\left(I C_{s}^{\prime \prime}\right) \text { and }(E C) \text {. }
$$


Let $r_{0}^{*}\left(r_{1}\right)$ denote the solution to this problem and define $\widehat{r}$ as

$$
Q^{\prime}\left(r_{0}=\widehat{r}\right)=1
$$

Further, let $\rho\left(r_{0}\right)$ denote the equilibrium separation threshold under an efficiency wage of $r_{0}$, i.e.

$$
Q\left(r_{0}\right)-\rho\left(r_{0}\right)=\bar{\pi}
$$

The next result characterizes the profit-maximizing efficiency wage.

Lemma 6. Conditional on $r_{1}$, the profit-maximizing efficiency wage is given by:

$$
r_{0}^{*}\left(r_{1}\right)=\left\{\begin{array}{l}
\widehat{r}, \text { if } r_{1} \leq \widehat{r}, \\
r_{1}, \text { if } \widehat{r}<r_{1} \leq r_{0}^{\max } \\
r_{0}^{\max }, \text { if } r_{0}^{\max }<r_{1} \leq \rho\left(r_{0}^{\max }\right) .
\end{array}\right.
$$

To understand the intuition behind Lemma 6, consider the costs and benefits of raising the efficiency wage from the perspective of the initial period. The marginal benefit of raising $r_{0}$ is given by $Q^{\prime}\left(r_{0}\right)$, whereas the marginal costs are equal to one if $r_{0} \geq r_{1}$ but zero if $r_{0}<r_{1}$. Then, by definition of $\widehat{r}$, if $\widehat{r}>r_{1}$, it is optimal to raise $r_{0}$ above $r_{1}$ and set it equal to $\widehat{r}$. By contrast, if $\widehat{r} \leq r_{1} \leq r_{0}^{\max }$, the principal's supergame profits are maximized for $r_{0}^{*}=r_{1}$. Intuitively, $r_{1}$ reflects the agent's outside option in terms of average per-period payoffs in the supergame. Thus, to accept the contract at date 1 , the agent requires $r_{1}$. But given that $r_{1}>\widehat{r}$ must be paid anyways to ensure participation, the principal can just as well implement $r_{1}$ as the efficiency wage, because $Q\left(r_{0}\right)$ is strictly increasing in $r_{0}$. Put differently, conditional on participation, any efficiency wage $r_{0} \leq r_{1}$ is "costless" in the sense that, from the perspective of date 1 , the principal does not have to admit a quasi-rent to the agent. In fact, the principal could raise her profits by setting $r_{0}=r_{1}$ for any $r_{1} \geq \widehat{r}$ with $d_{1}=1$, but for $r_{1} \in\left(r_{0}^{\max }, \rho\left(r_{0}^{\max }\right)\right]$, $r_{1}$ cannot be supported as an efficiency wage.

Thus, the model predicts that workers' compensation should not only depend on current outside options but also on the outside offers they entertained at the point in time when they formed the relationship with their current employer. Furthermore, the preceding considerations suggest that the contracting parties may have an incentive to renegotiate the efficiency wage upwards as their employment relationship progresses.

\subsection{Renegotiation}

While Lemma 6 shows that, conditional on observing $r_{1}$, the principal's preferred efficiency wage is larger for high than for low realizations of $r_{1}$, the agent clearly always prefers PPE with a efficiency wage. This observation implies that over the course of their relationship, the principal will be tempted to propose renegotiating the initial agreement. In particular, consider a relationship governed by the efficiency wage $r_{0}=\widehat{r}$ at some date $t$ with $r_{t}>\widehat{r}$. Lemma 6 implies that in such a situation, the principal would prefer to switch from $r_{0}=\widehat{r}$ to $r_{0}=r_{t}$, or 
$r_{0}=r_{0}^{\max }$, if $r_{0}=r_{t}$ is not self-enforcing. Further, the agent would be happy to accept such an offer to renegotiate $r_{0}$.

Thus, if the contracting parties are allowed to renegotiate the implicit agreement that determines the efficiency wage, the efficiency wage will increase over time. If early on, the agent entertains a relatively low outside option, the initial agreement will specify $r_{0}=\widehat{r}$. But as soon as the agent draws an outside option $r_{t}=\left(\widehat{r}, r_{0}^{\max }\right], r_{0}$ will permanently increase to $r_{t}$. Subsequently, the efficiency wage will increase again whenever $r_{\tau}>r_{t}$, for some $\tau>t$. Only if at some date, $r_{t}=r_{0}^{\max }$, the efficiency wage will cease to increase.

Thus, when we allow for renegotiation, the optimal incentive contract becomes non-stationary and the model predicts that the agent's average wage increases over time. Further, a higher efficiency wage lowers the agent's search effort level, thereby also reducing the separation rate. These predictions about the dynamic pattern of the employment relationship are highly consistent with empirical evidence on wage and turnover dynamics in real-life employment relationships. ${ }^{23}$ By contrast, most existing repeated principal-agent models are unable to generate such dynamics as these models typically focus on stationary trading environment.

\subsection{The Inefficiency}

The preceding analysis shows that in general, the PPE that principal and agent will coordinate on will be inefficient. Efficient effort incentives can in fact only be provided if $\rho^{*}$ can be supported as an efficiency wage, which requires that no trade ever takes place under A2. Further, even if $\rho^{*}$ can be sustained as an efficiency wage, the principal will never prefer to implement it, because she is always weakly better off turning to his next-best trading alternative. These results show that the mere possibility of the agent to improve his outside option via OJS creates agency costs. In fact, notice that environment studied in this paper features no frictions such as limited liability, risk aversion or incomplete contracts that are usually responsible for inefficient trade outcomes in moral hazard models. In any moral hazard model, efficient effort incentives require that the agent bears the full social consequences of his behavior. In a model without OJS, any increase in the agent's expected payoff due to more aligned incentives can be recouped by an appropriate up-front payment from the agent to the principal. By contrast, in the present model, search effort affects the expected value of future gains from trade and thereby the probability that trade should be conducted in future periods at all. Hence, efficient search incentives demand that the agent captures all gains from trade. When maximizing her profits, the principal therefore faces a tradeoff between rent-extraction and efficiency similar to the tradeoff in static moral hazard models with limited liability or risk aversion, yet with a completely different source of this tradeoff.

\footnotetext{
${ }^{23}$ See e.g. Farber (1999) and Topel and Ward (1992)
} 


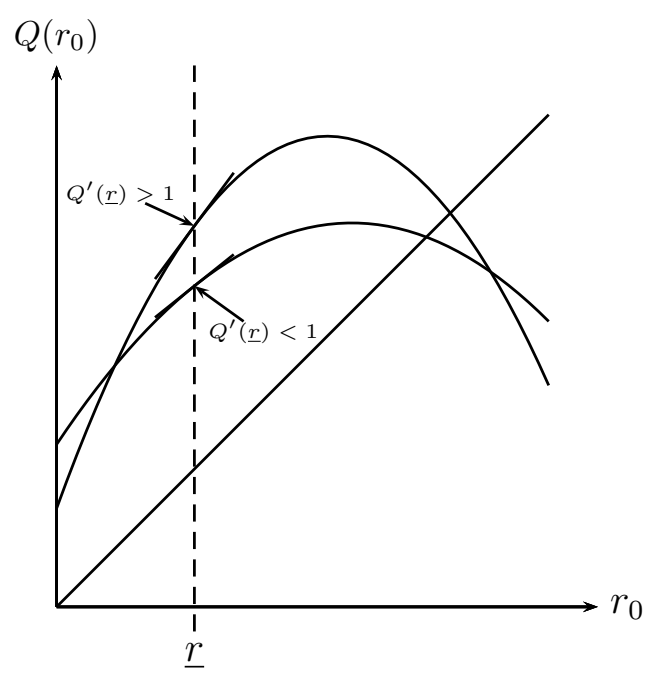

Figure 1: Fulfillment and violation of the existence condition.
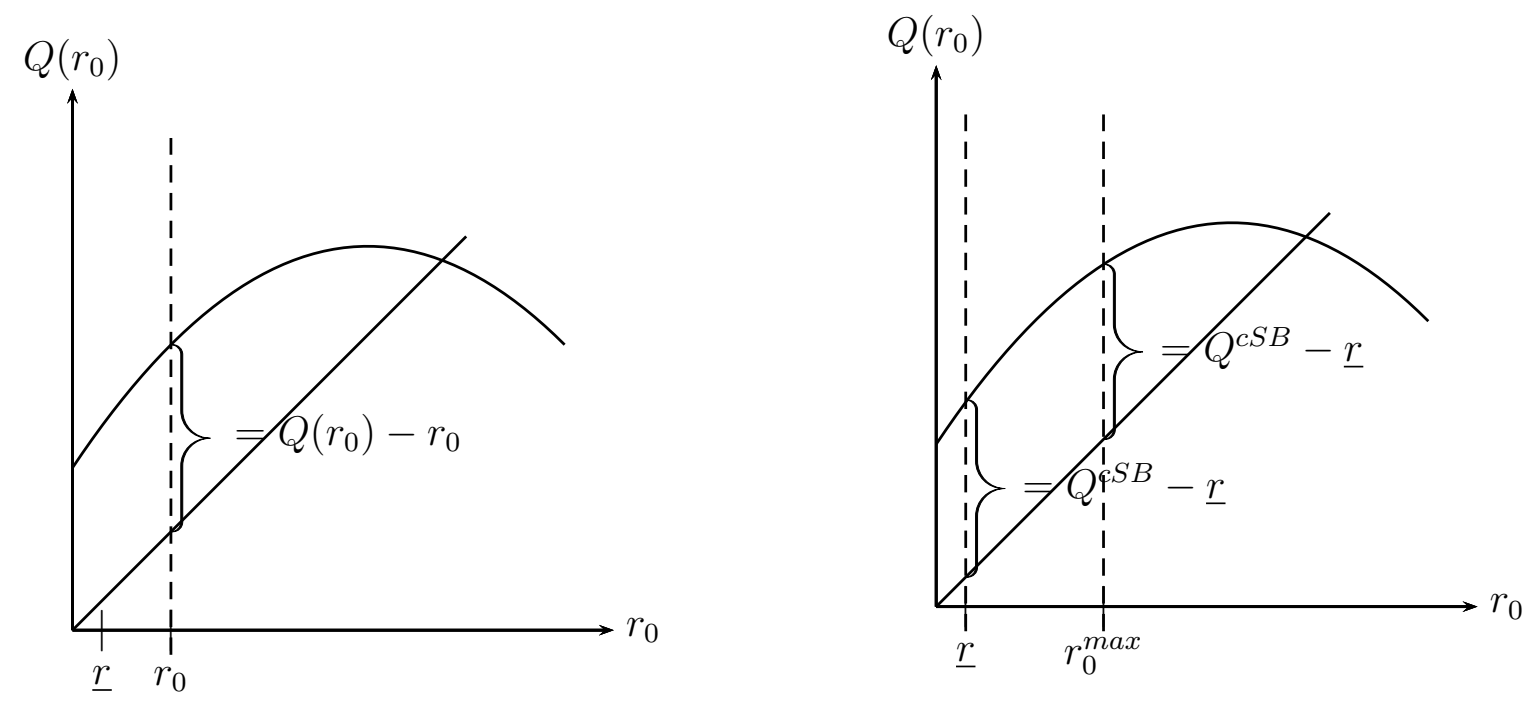

(a) Principal's profit for $r_{t} \in\left[\underline{r}, r_{0}\right]$.

(b) Range of self-enforcing efficiency wages $\left[\underline{r}, r_{0}^{\max }\right]$.

Figure 2 


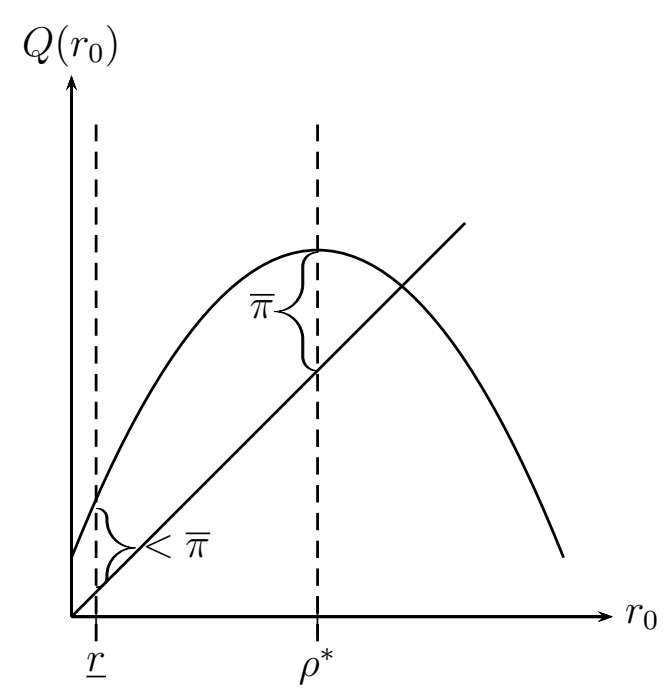

(a) No trade under A2.

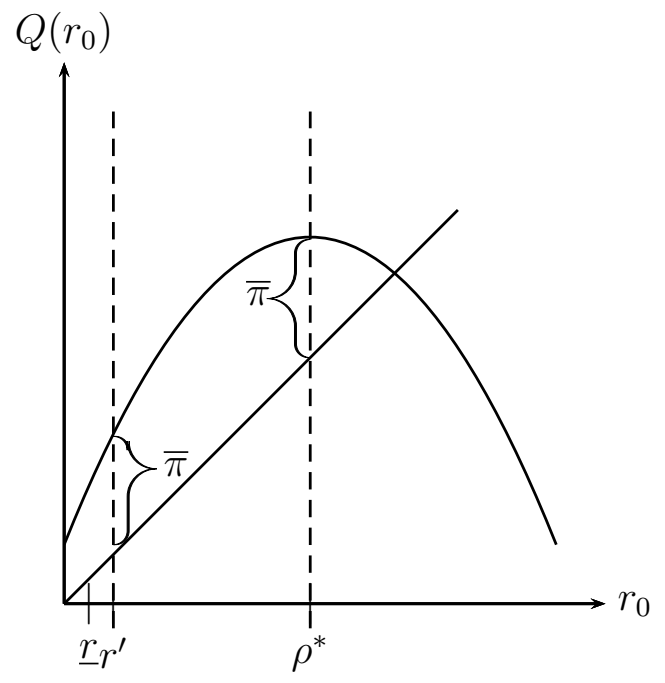

(b) Trade iff efficiency wage $r_{0} \in\left[r^{\prime}, \rho^{*}\right]$ is paid.

Figure 3

\section{Extensions}

\subsection{Long-Term Contracting}

Throughout the paper, it was assumed that the contracting parties could only write spot contracts, implying that any efficiency wage would have to be self-enforcing. Precluding parties from contracting ex-ante on $r_{t}$ seems like an appropriate assumption since information about workers' outside offers will in general be difficult to verify to third parties. Still, to understand the role of this assumption, this section examines how the paper's results change when the principal can commit to paying the efficiency wage $r_{0}$ whenever $r_{t} \leq r_{0}$.

Thus, suppose now that at date $t=1$, the principal can offer the agent an long-term contract specifying any efficiency wage $r_{0} \in[\underline{r}, \bar{r}]$ whose payment is court-enforceable whenever $r_{t} \leq r_{0}$. As under spot contracting, the profit-maximizing efficiency wage depends on $r_{1}$. Let $r_{0}^{c}$ denote the optimal efficiency wage threshold under commitment.

Lemma 7. When the principal can commit to paying the efficiency wage $r_{0} \in[\underline{r}, \bar{r}]$, the efficiency wage $r_{0}^{c}\left(r_{1}\right)$ that maximizes her profits conditional on $r_{1}$ is given by

$$
r_{0}^{c}\left(r_{1}\right)=\left\{\begin{array}{l}
\widehat{r}, \text { if } r_{1} \leq \widehat{r}, \\
r_{1}, \text { if } \widehat{r}<r_{1} \leq \rho^{*}
\end{array}\right.
$$

Lemma 7 shows that the principal's ability to commit to $r_{0}$ alters the profit-maximizing efficiency wage relative to the spot-contracting case only when in the latter, $(E C)$ is binding. It follows that if the long-term contract can be renegotiated, the efficiency wage could eventually 
be equal to $\rho^{*}$. However, we can have $r_{0}^{c}=\rho^{*}$ only if $\rho^{*}$ realizes exactly in some period. Otherwise, the relationship either continues to be inefficient or severs.

Thus, even under commitment, equilibrium is generally inefficient and total surplus is maximized only in very rare cases. Implementing efficient effort incentives would require that the principal commits to surrendering all gains from trade to the agent. By the same argument as under spot-contracting, such a strategy can never be optimal for the principal. In other words, even when the principal decides about the optimal long-term contract, she still faces a tradeoff between efficiency and rent-extraction.

\subsection{Unverifiable Output}

Throughout the analysis, it was assumed that output $y$ is verifiable and can hence be used as a basis for an output-contingent bonus contract. However, in many jobs, especially for highskilled workers, performance is notoriously difficult to assess objectively, let alone verify to third parties. A growing literature studies how the incentive problems that result under such incomplete contracting settings can be mitigated with the help of relational incentive contracts, implicit agreements that are sustained by the value of ongoing trade. ${ }^{24}$ In this section, I derive and analyze the profit-maximizing relational incentive contract that the principal offers when output is non-verifiable and the agent performs OJS.

Thus, suppose that $y$ can no longer be used as the basis of a formal incentive contract. Instead, the bonus payment $b$ must be self-enforcing. In particular, suppose that at date $t=1$, the principal offers the agent a relational incentive contract, promising to pay the bonus $b_{t}=b>0$ whenever $y_{t}=\bar{y}$ (and $d_{t}=1$ ). Further, suppose that conditional on accepting this implicit contract, the agent terminates the relationship whenever the principal fails to pay $b$ when $y_{t}=\bar{y}$, i.e. his strategy prescribes $d_{t}=0$ if $y_{t-1}=\bar{y}$ and $b_{t-1}=0$. Since players cannot do worse than receive their current outside options ad infinitum, such a response to a deviation by the principal constitutes an optimal punishment in the sense of Abreu, Pearce, and Stacchetti (1990).

Without loss of generality, suppose that the principal seeks to implement a stationary effort profile $(e, s)$ and hence offers the stationary relational incentive contract $\left(w_{t}, \bar{b}_{t}\right)=\left(w\left(r_{t}\right), b\right)$. I proceed as in section 4 by starting with the case in which the agent receives no rent from the employment relationship. In that case, players' payoff functions and the incentive compatibility constraints governing the agent's choice of $(e, s)$ are identical to those in section 4.1. The difference is that the bonus payment must be self-enforcing, which adds another constraint to the principal's problem. To see which levels of $b$ are self-enforcing, consider the principal's decision problem at the end of some period $t$ with $y_{t}=\bar{y}$. Conditional on the separation threshold $\rho$, if she pays the bonus $b$ as promised, her continuation payoff is

$$
-(1-\delta) b+\delta\{G(\rho \mid s)[Q(e, s)-\mathbb{E}(r \mid r \leq \rho, s)]+[1-G(\rho \mid s)] \bar{\pi}\} .
$$

\footnotetext{
${ }^{24}$ See section 2 for references.
} 
If she withholds the bonus, the agent severs the relationship which implies a continuation payoff of $\delta \bar{\pi}$. Thus, a stationary bonus payment $b$ that implements effort profile $(e, s)$ is self-enforcing if and only if $\delta \bar{\pi}$ is no greater than the principal's continuation payoff when complying with the relational contract. This leads to the following dynamic enforcement constraint, which states that any self-enforcing bonus payment must satisfy:

$$
(1-\delta) b \leq \delta G(\rho \mid s)[Q(e, s)-\mathbb{E}(r \mid r \leq \rho, s)-\bar{\pi}]
$$

Defining $b^{\max }(e, s)$ as the maximum bonus payment that is self-enforcing under effort profile $(e, s),(D E)$ can be rewritten as

$$
b \leq b^{\max }(e, s) \equiv \frac{\delta}{1-\delta} G(\rho \mid s)[Q(e, s)-\mathbb{E}(r \mid r \leq \rho, s)-\bar{\pi}]
$$

The maximum bonus payment that the principal can credibly promise to pay is equal to the discounted rent that she expects to receive from the end of date $t$ onwards if the relationship is continued. If $b^{c S B} \leq b^{\max }\left(e^{c S B}, s^{c S B}\right)$, the profit-maximizing allocation under verifiable output can be implemented with a relational contract. Therefore, in the remainder of this section, I will focus on the interesting case in which $b^{c S B}>b^{\max }\left(e^{c S B}, s^{c S B}\right)$, i.e. in which the profitmaximizing bonus payment cannot be supported by a relational incentive contract.

Lemma 8. If $b$ is not enforceable and $b^{c S B}>b^{\max }\left(e^{c S B}, s^{c S B}\right)$, the profit-maximizing bonus payment, $b^{I C}$, is given by

$$
b^{I C}=\frac{\delta}{1-\delta} G\left(\rho^{I C} \mid s\left(b^{I C}\right)\right)\left[Q\left(b^{I C}\right)-\mathbb{E}\left(r \mid r \leq \rho^{I C}, s\left(b^{I C}\right)\right)-\bar{\pi}\right] .
$$

Further, $Q\left(b^{I C}\right)<Q^{c S B}$ and $\rho^{I C}<\rho^{*}$.

Thus, if $b^{c S B}>b^{\max }\left(e^{c S B}, s^{c S B}\right)$, incomplete contracting aggravates the inefficiency since the principal is forced to implement an even lower level of total surplus than $Q^{c S B}$. Next, consider the effect of introducing an efficiency wage $r_{0}>\underline{r}$. When $b^{c S B}>b^{\max }\left(e^{c S B}, s^{c S B}\right)$, the principal would like to raise $b$ above $b^{I C}$, but $(D E)$ prevents her from doing so. Hence, at $\left(b, r_{0}\right)=\left(b^{I C}, \underline{r}\right):$

$$
\frac{\partial Q(e, s)}{\partial b}=Q_{e} \frac{\partial e}{\partial b}+Q_{s} \frac{\partial s}{\partial b}>0
$$

and thus also:

$$
\frac{\partial Q(e, s)}{\partial r_{0}}=Q_{e} \frac{\partial e}{\partial r_{0}}+Q_{s} \frac{\partial s}{\partial r_{0}}>0 .
$$

When $b^{c S B}>b^{\max }\left(e^{c S B}, s^{c S B}\right)$, then at $\left(b, r_{0}\right)=\left(b^{I C}, \underline{r}\right)$, either $Q_{e}>0$ and $Q_{s}<0$ or $Q_{e}<0$ and $Q_{s}<0$. In the former case, increasing $r_{0}$ clearly raises total surplus, because $e(s)$ is increasing (decreasing) in $r_{0}$. In the latter case, paying an efficiency wage raises total surplus as well, because, as under the constrained second-best solution, $r_{0}$ involves a more favorable tradeoff between raising $e$ and lowering $s$ than $b$.

Yet, under relational contracting, raising the efficiency wage has an additional effect. When 
$(D E)$ is binding, raising $r_{0}$ relaxes $(D E)$, thereby enabling the principal to provide more highpowered incentives via the bonus scheme. More precisely, $r_{0}$ raises $b^{\text {max }}$ only if the associated gain in surplus outweighs the increase in the principal's wage bill. Yet, when $r_{0}>\underline{r}$, the agent earns a rent from employment, which can be used to induce him to pay a fine $-\underline{b}>0$ to the principal whenever $y_{t}=y$. Therefore, consider the relational contract that prescribes that the principal pays $\bar{b}>0$ to the agent if $y_{t}=\bar{y}$ and that the agent pays $-\underline{b}>0$ to the principal if $y_{t}=\underline{y}$. Further, suppose that the principal terminates the relationship if the agent fails to pay the fine when $y_{t}=\underline{y}$. Complying with this relational contract when $y_{t}=\underline{y}$ yields the agent a continuation payoff of

$$
(1-\delta) \underline{b}+\delta\left[G\left(r_{0} \mid s\right) r_{0}+\int_{r_{0}}^{\bar{r}} r g(r \mid s) d r\right] .
$$

Instead, refusing to pay the fine and inducing severance implies a payoff of

$$
\delta \int_{\underline{r}}^{\bar{r}} r g(r \mid s) d r
$$

Hence, the payment of the fine is self-enforcing if and only if

$$
-\underline{b} \leq \frac{\delta}{1-\delta} \int_{\underline{r}}^{r_{0}}\left(r_{0}-r\right) g(r \mid s) d r .
$$

Let $-\underline{b}^{\text {min }}(s)$ denote the maximum fine the agent can be induced to pay given search effort level $s$ :

$$
-\underline{b}^{\text {min }}(s) \equiv \frac{\delta}{1-\delta} \int_{\underline{r}}^{r_{0}}\left(r_{0}-r\right) g(r \mid s) d r \geq 0 .
$$

The incentives to exert work effort are increasing in $\Delta b \equiv \bar{b}-\underline{b}$. Thus, given $r_{0}$, the highestpowered work effort incentives that can be sustained under any relational contract that implements $(e, s)$ are given by $\Delta b^{\max }(e, s) \equiv b^{\max }(e, s)-\underline{b}^{\min }(s)$. Using the definitions of $b^{\max }$ and $\underline{b}^{\text {min }}$, the next result follows:

Lemma 9. For every $(e, s), \Delta b^{\max }(e, s)$ is strictly increasing in $r_{0} \in\left[\bar{r}, \rho^{*}\right]$.

So, the size of the highest-powered work effort incentives that can be implemented with a relational contract is the greater, the higher the efficiency wage that the agent receives. Thus, when work effort incentives are provided via relational incentive contracts, efficiency wages increase the scope for high-powered work effort incentives. Taking this effect into account, the overall impact of introducing an efficiency wage on total surplus is:

$$
\left.\frac{\partial Q(e, s)}{\partial r_{0}}\right|_{\left(\Delta b, r_{0}\right)=\left(b^{I C}, \underline{r}\right)}=Q_{e} \frac{\partial e}{\partial r_{0}}+Q_{s} \frac{\partial s}{\partial r_{0}}+\frac{\partial Q(e, s)}{\partial b} \frac{\partial b}{\partial r_{0}} .
$$

By lemma 9, when $(D E)$ binds, the last term in this expression is strictly positive. Hence, the marginal benefit of introducing an efficiency wage is strictly larger when bonus payments are not legally enforceable. In that sense, incomplete contracting makes an even stronger case for the use of efficiency wages when the agent can perform on-the-job search. 


\subsection{Limited Liability}

Throughout the analysis, the assumption that the principal could offer the agent a contract with a negative fixed wage played a crucial role in deriving the optimal contract. Since $b\left(r_{0}\right) \geq \Delta y$ for all $r_{0} \in[\underline{r}, \bar{r}]$, any profit-maximizing contract would specify a negative fixed-wage component. In this section, I derive the profit-maximizing incentive contract when the agent is protected by limited liability. I.e., I analyze the model under the restriction

$$
W_{t}=w_{t}+b_{t} \geq 0 \text { for any } t
$$

Under $(L L)$ the profit-maximizing incentive contract will differ from the one derived in sections 4 and ??. As a first step, I show that the profit-maximizing contract under limited liability is non-stationary. To this purpose, suppose for the time being that the principal offers the same contract $\left(w_{t}, \bar{b}_{t}\right)=(0, b)$ at every date $t$ with $d_{t}=1$. As such a contract will induce a stationary effort profile, the principal's profits at any date $t$ with $d_{t}=1$, given separation threshold $\rho^{\prime}$, are

$$
\pi=(1-\delta)[\underline{y}+f(e)(\Delta y-b)]+\delta\left(G\left(\rho^{\prime} \mid s\right) \pi+\left[1-G\left(\rho^{\prime} \mid s\right)\right] \bar{\pi}\right),
$$

which is equivalent to

$$
\pi=\frac{1-\delta}{1-\delta G\left(\rho^{\prime} \mid s\right)}[\underline{y}+f(e)(\Delta y-b)]+\frac{\delta\left[1-G\left(\rho^{\prime} \mid s\right)\right]}{1-\delta G\left(\rho^{\prime} \mid s\right)} \bar{\pi} .
$$

As this expression indicates, under limited liability, the principal derives no value from a positive search level because her inability to offer negative wages prevents her from extracting the agent's discounted benefits from search effort. Hence, under $(L L)$, the principal prefers to induce as little search effort as possible. The agent's payoff given $b$ and $\rho^{\prime}$ at some date $t$ with $d_{t}=1$ is

$$
u=(1-\delta)[f(e) b-c(e+s)]+\delta\left[G\left(\rho^{\prime} \mid s\right) u+\int_{\rho^{\prime}}^{\bar{r}} r g(r \mid s) d r\right]
$$

The agent will accept the principal's offer as long as $u \geq r_{t}$. Hence, in equilibrium, the separation threshold, is just equal to the agent's equilibrium payoff, i.e. $u=\rho^{\prime}$. The agent therefore chooses $(e, s)$ for any contract offer $b$ as to maximize the separation threshold

$$
\rho^{\prime}=\frac{1-\delta}{1-\delta G\left(\rho^{\prime} \mid s\right)}[f(e) b-c(e+s)]+\frac{\delta}{1-\delta G\left(\rho^{\prime} \mid s\right)} \int_{\rho^{\prime}}^{\bar{r}} r g(r \mid s) d r
$$

Observe that this expression defines $\rho^{\prime}$ implicitly. Using the implicit function theorem, the first-order conditions, characterizing the agent's choice of $(e, s)$ are

$$
\begin{gathered}
f^{\prime}(e) b=c^{\prime}(e+s), \\
\frac{\delta}{1-\delta}\left[G_{s}\left(\rho^{\prime} \mid s\right) \rho^{\prime}+\int_{\rho^{\prime}}^{\bar{r}} r g_{s}(r \mid s) d r\right]=c^{\prime}(e+s) .
\end{gathered}
$$


These conditions indicate that the limited-liability constraint prevents the principal from choosing $b$ and $r_{0}$ independently. Under $(L L)$, the agent earns a rent for every $r<\rho^{\prime}$. Hence, his incentive compatibility constraints are identical to $\left(I C_{e}\right)$ and $\left(I C_{s}^{\prime \prime}\right)$ with an efficiency wage threshold of $r_{0}=\rho^{\prime}$. Thus, his behavioral response to changes in $b$ and $r_{0}=\rho^{\prime}$ is equivalent to the one derived in section 4 . However, when changing $b$, the principal simultaneously affects the agent's limited liability rent and hence the efficiency wage threshold $r_{0}=\rho^{\prime}$. Let $\rho^{\prime}(b)$ be the agent's equilibrium payoff when $d_{t}=1$ as a function of the stationary contract $b$. By the envelope theorem

$$
\frac{\partial \rho^{\prime}(b)}{\partial b}=\frac{1-\delta}{1-\delta G\left(\rho^{\prime}(b) \mid s\right)} f(e)>0 .
$$

Given the agent's incentive compatibility constraints, the principal's problem is to choose $b$ as to maximize $\pi$. The first-order condition of this problem is

$$
\begin{aligned}
\frac{\partial \pi}{\partial b} & =f^{\prime}(e)(\Delta y-b) \frac{\partial e}{\partial b} \\
& +\frac{\delta G_{s}\left(\rho^{\prime}(b) \mid s\right)}{1-\delta G\left(\rho^{\prime}(b) \mid s\right)}[f(e)(\Delta y-b)-\bar{\pi}] \frac{\partial s}{\partial b} \\
& +\frac{\delta(1-\delta) g\left(\rho^{\prime}(b) \mid s\right)}{\left[1-\delta G\left(\rho^{\prime}(b) \mid s\right)\right]^{2}}[f(e)(\Delta y-b)-\bar{\pi}] f(e) \\
& -f(e)=0 .
\end{aligned}
$$

The first part of this expression represents the increase in profits due to a higher work effort level, while the second part reflects the benefits of a reduced search effort level. A lower search level raises the continuation probability, which is valued by the principal, because $\pi \geq \bar{\pi}^{25}$ As reflected by the third term, the continuation probability is also raised through an increase in $\rho^{\prime}(b)$. Finally, the fourth term represents the first-order wage costs of a marginal increase in $b$.

Let $b^{\prime}$ denote the solution to the principal's problem and let $\pi^{\prime}$ denote the implied profit level. Clearly, a contract will only be offered if $\pi^{\prime} \geq \pi$. However, for any date $t$ with $r_{t}>\rho^{\prime}\left(b^{\prime}\right)$, if $\pi^{\prime}-\left(r_{t}-\rho^{\prime}\left(b^{\prime}\right)\right) \geq \bar{\pi}$, the principal can offer the agent a contract that yields him exactly $r_{t}$ and which he would therefore accept. Further, such an offer would yield the principal a profit weakly larger than $\bar{\pi}$. It follows that the profit-maximizing contract cannot be stationary. The next result characterizes the non-stationary incentive contract that maximizes the principal's profits under $(L L)$.

\footnotetext{
${ }^{25}$ If $\pi \leq \bar{\pi}$, the principal would not offer a contract in the first place.
} 
Lemma 10. When the agent is protected by limited liability (i.e., when (LL) holds), the principal offers ...

(i) ... for all $t$ with $r_{t} \leq r_{0}^{l}$, a constant bonus $b_{0}^{l}$, inducing a constant effort profile $\left(e_{0}^{l}, s_{0}^{l}\right)$,

(ii) ... for $t$ with $r_{0}^{l}<r_{t} \leq \rho^{l}$, a bonus $b^{l}\left(r_{t}\right)$ that is strictly increasing in $r_{t}$ and that induces an effort profile $\left(e^{l}\left(r_{t}\right), s^{l}\left(r_{t}\right)\right)$ with $e(s)$ being strictly increasing (decreasing) in $r_{t}$.

(iii) For all $t$ with $r_{t} \leq r_{0}^{l}$, the principal receives the constant profit $\pi_{0}^{l}$, while the agent receives the constant payoff $r_{0}^{l}$.

(iv) For $t$ with $r_{0}^{l}<r_{t} \leq \rho^{l}$, the principal receives the profit $\pi^{l}\left(r_{t}\right)$ which is strictly decreasing in $r_{t}$, while the agent receives $r_{t}$.

(v) The equilibrium separation threshold $\rho^{l}$ is defined by $\pi^{l}\left(\rho^{l}\right)=\bar{\pi}$.

Under this contract, the principal cannot raise her profits by deviating to some other offer for any $r_{t} \in[\underline{r}, \bar{r}]$. The bonus $b_{0}^{l}$ maximizes the principal's profits given $(L L)$ and given the continuation play specified in lemma 10, i.e., it solves the following first-order condition

$$
\begin{aligned}
\frac{\partial \pi}{\partial b} & =f^{\prime}(e)(\Delta y-b) \frac{\partial e}{\partial b} \\
& +\frac{\delta}{1-\delta}\left[G_{s}\left(r_{0}^{l}\right) \pi_{0}^{l}+\int_{r_{0}^{l}}^{\rho^{l}} \pi^{l}\left(r_{t}\right) g_{s}(r \mid s) d r-G_{s}\left(r^{T, l} \mid s\right) \bar{\pi}\right] \frac{\partial s}{\partial b} \\
& +\frac{\delta g\left(r_{0}^{l} \mid s\right)}{1-\delta G\left(r_{0}^{l} \mid s\right)}\left[\pi_{0}^{l}-\pi\left(r_{0}^{l}\right)\right] f(e) \\
& -f(e)=0 .
\end{aligned}
$$

The interpretation of the individual terms in this expression is equivalent to the first-order condition for the stationary contract. However, the third term is only positive if the switch from $b_{0}^{l}$ to $b^{l}\left(r_{t}\right)$ at $r_{t}=r_{0}^{l}$ generates a discontinuity in the principal's profit function. Further, by construction:

$$
\left.\frac{\partial \pi}{\partial b}\right|_{b=b^{l}\left(r_{t}\right)}<0, \text { for all } r_{0}^{l}<r_{t} \leq \rho^{l}
$$

Hence, $\pi^{l}\left(r_{t}\right)$ is decreasing in $r_{t}$, implying that the termination threshold $\rho^{l}$ is defined by the agent's outside option for which $\pi^{l}\left(r_{t}\right)=\bar{\pi}$.

Further, notice that the profit-maximizing incentive contract has $w_{t}=0$ for all $t$, because when $r_{t}>r_{0}^{l}$, it is more profitable for the principal to raise the agent's payoff via $b$ instead of $w$. Intuitively, while an increase in $w$ represents a mere transfer from the principal to the agent, increasing $b$ raises total surplus in addition to the agent's payoff. Thus, the principal can achieve a given increase of the agent's payoff more cheaply by raising $b$ than by raising $w$.

Finally, note that the rent $r_{0}^{l}$ that the agent receives is not a pure limited-liability rent. As argued above, under limited liability, an increase in $b$ affects the agent's incentives via two channels. First, by raising the marginal benefits of work effort and second by increasing 
$r_{0}^{l}$ which reduces the agent's marginal search benefits. Taking this latter effect into account, the marginal effects $\partial e / \partial b$ and $|\partial s / \partial b|$ are greater than in a model without on-the-job search. Hence, the possibility to perform on-the-job search raises the agent's limited-liability rent.

\section{Conclusion}

One of the key objectives of incentive theory is to explain the shape of compensation contracts that we observe in real-life employment relationships. This paper has demonstrated that several properties common to many compensation contracts observed in the labor market can be better understood by studying how workers' incentives to prompt competition for their services through on-the-job search (OJS) interact with the moral hazard problem inherent in most employment relationships. In recent decades, the competition among firms for the most highly talented workers in the market has intensified, leading to better outside options for employees and to larger returns from conducting OJS. I have shown that when the agent can perform OJS, the optimal incentive contract entails a larger bonus component and leaves a larger share of the created surplus to the agent than in the absence of OJS. Indeed, the use of performance pay in employment contracts and the levels of pay has risen substantially over the last thirty years. In particular, high-skill workers, whose services are most intensely competed for, are found to receive more performance pay on average and have higher degrees of bargaining power compared to low-skill workers. Further, when allowing for renegotiation, the model predicts that average wages increase with tenure, while separation rates decrease with tenure, two well-established attributes of observed employment relationships. From a more formal viewpoint, the model rationalizes the use of efficiency wages in a much broader class of monitoring environments, namely also in those in which the employer can only observe a noisy signal of the agent's effort choice. The reason is that with OJS, efficiency wages and bonus payments are complementary rather than substitutable. Hence, the model can rationalize the joint use of several incentive instruments without having to assume frictions such as incomplete contracting or limited liability. While the model in this paper focuses on the interaction between one principal and one agent, a next step in the analysis would be to study the interaction between OJS and moral hazard problem in a general equilibrium model of a market economy. 


\section{Appendix}

\section{A Symmetric Information}

Proof of Lemma 1. Consider some date $t$ with $d_{t}=1$. The principal's and agent's payoffs respectively are given by:

$$
\begin{gathered}
\pi_{t}=(1-\delta)\left[\underline{y}+f\left(e_{t}\right) \Delta y-w_{t}\right]+\delta \mathbb{E}_{r}\left[\pi_{t+1} \mid s_{t}\right] \\
u_{t}=(1-\delta)\left[w_{t}-c\left(e_{t}+s_{t}\right)\right]+\delta \mathbb{E}_{r}\left[u_{t+1} \mid s_{t}\right]
\end{gathered}
$$

Total surplus is thus given by

$$
Q_{t}=(1-\delta)\left[\underline{y}+f\left(e_{t}\right) \Delta y-c\left(e_{t}+s_{t}\right)\right]+\delta \mathbb{E}_{r}\left[Q_{t+1} \mid s_{t}\right]
$$

Note that total surplus is independent of $r_{t}$. Let $Q^{S I}$ be the maximum surplus that can be generated when $d_{t}=1$. By A1, there is some $\rho^{*}<\bar{r}$ such that $\bar{\pi}+r>Q^{S I}$ for all $r>\rho^{*}$. Hence, $(P C)$ implies that $d_{t}=0$ whenever $r_{t}>\rho^{*}$. When $\bar{\pi}+r_{t} \leq Q^{S I}$, the principal maximizes her profits by offering the agent a contract that implements $Q^{S I}$ and pays the agent $r_{t}$. Given $\left(e_{t}, s_{t}\right)$ and $b_{t}$, this is achieved with a fixed-wage equal to

$$
w_{t}=\frac{r_{t}}{1-\delta}+c\left(e_{t}+s_{t}\right)-\frac{\delta}{1-\delta} \mathbb{E}\left(u_{t+1}\right)
$$

This proves item (i). Further, by $(P C), d_{t}=1$ if and only if $Q^{S I}-r_{t} \geq \bar{\pi}$, which proves item (ii).

Further, $Q_{t+1}=Q^{S I}$ if $r_{t+1} \leq \rho^{*} \equiv Q^{S I}-\bar{\pi}$ and $Q_{t+1}=\bar{\pi}+r_{t+1}$ if $r_{t+1}>\rho^{*}$. Thus, total surplus can be written as:

$$
Q_{t}=(1-\delta)\left[\underline{y}+f\left(e_{t}\right) \Delta y-c\left(e_{t}+s_{t}\right)\right]+\delta\left\{G\left(\rho^{*} \mid s_{t}\right) Q^{S I}+\left[1-G\left(\rho^{*} \mid s_{t}\right)\right]\left[\bar{\pi}+\mathbb{E}_{r}\left(r_{t+1} \mid r_{t+1}>\rho^{*}, s_{t}\right)\right]\right\}
$$

Since $Q_{t}=Q^{S I}$ as well, we have:

$$
Q_{t}=Q^{S I}=\frac{1-\delta}{1-\delta G\left(\rho^{*} \mid s_{t}\right)}\left[\underline{y}+f\left(e_{t}\right) \Delta y-c\left(e_{t}+s_{t}\right)\right]+\frac{\delta\left[1-G\left(\rho^{*} \mid s_{t}\right)\right]}{1-\delta G\left(\rho^{*} \mid s_{t}\right)}\left[\bar{\pi}+\mathbb{E}_{r}\left(r_{t+1} \mid r_{t+1}>\rho^{*}, s_{t}\right)\right] .
$$

Thus, at any date $t$ with $r_{t} \leq \rho^{*}$, the principal faces the same maximization problem and hence always chooses the effort profile $\left(e^{S I}, s^{S I}\right)$ that implements $Q^{S I}$. This proves item (iii).

Optimal Separation Threshold. Consider some effort profile $(e, s)$ and an arbitrary separation threshold $\rho$ and define $\bar{\rho}(\rho) \equiv Q(e, s, \rho)-\bar{\pi}$. $(P C)$ implies that for any PPE, $\rho^{E Q}=\bar{\rho}\left(\rho^{E Q}\right)$. Thus, for any $(e, s)$ that constitutes a PPE, the equilibrium separation threshold $\rho^{E Q}$ is defined by the implicit function:

$$
R\left(e, s, \rho^{E Q}\right)=Q\left(e, s, \rho^{E Q}\right)-\bar{\pi}-\rho^{E Q}=0 .
$$

Differentiating $R$ with respect to $\rho^{E Q}$ gives

$$
\frac{\partial R\left(e, s, \rho^{E Q}\right)}{\partial \rho^{E Q}}=\frac{\partial Q\left(e, s, \rho^{E Q}\right)}{\partial \rho^{E Q}}-1=-\left[1-G\left(\rho^{E Q} \mid s\right)\right] .
$$


Thus, by the implicit function theorem, the marginal effect of $x=e, s$ on $Q$ is given by:

$$
\begin{aligned}
Q_{x} & =\frac{\partial Q\left(e, s, \rho^{E Q}\right)}{\partial x}+\frac{\partial Q\left(e, s, \rho^{E Q}\right)}{\partial \rho^{E Q}} \frac{\partial \rho^{E Q}}{\partial x} \\
& =\frac{\partial Q\left(e, s, \rho^{E Q}\right)}{\partial x}+G\left(\rho^{E Q} \mid s\right) \frac{\frac{\partial R\left(e, s, \rho^{E Q}\right)}{\partial x}}{\left[1-G\left(\rho^{E Q} \mid s\right)\right]} \\
& =\frac{\partial Q\left(e, s, \rho^{E Q}\right)}{\partial x}+G\left(\rho^{E Q} \mid s\right) \frac{\frac{\partial Q\left(e, s, \rho^{E Q}\right)}{\partial x}}{1-G\left(\rho^{E Q} \mid s\right)} \\
& =\frac{\partial Q\left(e, s, \rho^{E Q}\right)}{\partial x} \frac{1}{1-G\left(\rho^{E Q} \mid s\right)} .
\end{aligned}
$$

First-Order Conditions. Under symmetric information, the principal chooses $(e, s)$ as to maximize $Q(e, s)$ subject to $R\left(e, s, \rho^{*}\right)=0$. This problem's first-order conditions are:

$$
\begin{aligned}
& Q_{e}=\frac{\partial Q\left(e, s, \rho^{*}\right)}{\partial e}+\frac{\partial Q\left(e, s, \rho^{*}\right)}{\partial \rho^{*}} \frac{\partial \rho^{*}}{\partial e}=0 \\
& Q_{s}=\frac{\partial Q\left(e, s, \rho^{*}\right)}{\partial s}+\frac{\partial Q\left(e, s, \rho^{*}\right)}{\partial \rho^{*}} \frac{\partial \rho^{*}}{\partial s}=0 .
\end{aligned}
$$

By the implicit function theorem:

$$
\begin{gathered}
\frac{\partial \rho^{*}}{\partial e}=-\frac{\frac{\partial R\left(e, s, \rho^{*}\right)}{\partial e}}{\frac{\partial R\left(e, s, \rho^{*}\right)}{\partial \rho^{*}}}=-\frac{\partial Q\left(e, s, \rho^{*}\right)}{\partial e} \frac{-1}{1-G\left(\rho^{*} \mid s\right)}, \\
\frac{\partial \rho^{*}}{\partial s}=-\frac{\frac{\partial R\left(e, s, \rho^{*}\right)}{\partial s}}{\frac{\partial R\left(e, s, \rho^{*}\right)}{\partial \rho^{*}}}=-\frac{\partial Q\left(e, s, \rho^{*}\right)}{\partial s} \frac{-1}{1-G\left(\rho^{*} \mid s\right)} .
\end{gathered}
$$

Using (A.1), (A.4) and (A.5), (A.2) and (A.3) can be rewritten as:

$$
\begin{aligned}
& Q_{e}=\frac{\partial Q\left(e, s, \rho^{*}\right)}{\partial e} \frac{1}{1-G\left(\rho^{*} \mid s\right)}=0 \\
& Q_{s}=\frac{\partial Q\left(e, s, \rho^{*}\right)}{\partial s} \frac{1}{1-G\left(\rho^{*} \mid s\right)}=0 .
\end{aligned}
$$

Further, since $G\left(\rho^{*} \mid s\right)<1$ under A1, the first-order conditions of the principal's problem can be restated as:

$$
\begin{gathered}
Q_{e}=\frac{\partial Q\left(e, s, \rho^{*}\right)}{\partial e}=0 \\
Q_{s}=\frac{\partial Q\left(e, s, \rho^{*}\right)}{\partial s}=0 .
\end{gathered}
$$

Second-Order Conditions. The second-order derivative of $Q(e, s)$ with respect to $e$ is:

$$
Q_{e e}=\frac{1-\delta}{\left[1-\delta G\left(\rho^{*} \mid s\right)\right]^{2}}\left[f^{\prime \prime}(e) \Delta y-c^{\prime \prime}(e+s)\right]<0
$$


The second-order derivative of $Q(e, s)$ with respect to $s$ is:

$$
\begin{aligned}
Q_{s s} & =-\frac{1-\delta}{1-\delta G\left(\rho^{*} \mid s\right)} c^{\prime \prime}(e+s) \\
& +\frac{\delta}{1-\delta G\left(\rho^{*} \mid s\right)}\left[2 G_{s}\left(\rho^{*} \mid s\right) \frac{\partial \mathbb{E}\left(r \mid r>\rho^{*}, s\right)}{\partial s}+G_{s s}\left(\rho^{*} \mid s\right) \mathbb{E}\left(r \mid r>\rho^{*}, s\right)+\int_{\rho^{*}}^{\bar{r}} r g_{s s}(r \mid s) d r\right] \\
& -\frac{2 \delta(1-\delta) G_{s}\left(\rho^{*} \mid s\right)}{\left[1-\delta G\left(\rho^{*} \mid s\right)^{2}\right.}\left[c^{\prime}(e+s)+\frac{\partial \mathbb{E}\left(r \mid r>\rho^{*}, s\right)}{\partial s}\right] \\
& +\frac{\delta(1-\delta)}{\left[1-\delta G\left(\rho^{*} \mid s\right)\right]^{3}}\left[\left(1-\delta G\left(\rho^{*} \mid s\right)\right) G_{s s}\left(\rho^{*} \mid s\right)+2 \delta\left[G_{s}\left(\rho^{*} \mid s\right)\right]^{2}\right]\left[T(e, s)-\mathbb{E}\left(r \mid r>\rho^{*}, s\right)-\bar{\pi}\right] .
\end{aligned}
$$

While the first, second and fourth term in this expression are negative, the third term is positive. Intuitively, as $s$ increases, the weight attached to $T(e, s)$ and hence to the marginal costs of effort $c^{\prime}(e+s)$ decreases, while the weight attached to the payoff under separation and hence the marginal benefit of increasing that payoff increase. For $Q_{s s}$ to be negative, this effect must be sufficiently small relative to the effects captured by terms 1,2 and 4 .

Using $\left(S I C_{s}\right)$ and collecting terms, (A.7) can be simplified to:

$$
\begin{aligned}
Q_{s s} & =\frac{-(1-\delta)}{1-\delta G\left(\rho^{*} \mid s\right)} c^{\prime \prime}(e+s) \\
& +\frac{\delta}{1-\delta G\left(\rho^{*} \mid s\right)}\left[G_{s s}\left(\rho^{*} \mid s\right) \mathbb{E}\left(r \mid r>\rho^{*}, s\right)+\int_{\rho^{*}}^{\bar{r}} r g_{s s}(r \mid s) d r\right] \\
& +\frac{\delta(1-\delta)}{\left[1-\delta G\left(\rho^{*} \mid s\right)\right]^{2}}\left[\left(1-\delta G\left(\rho^{*} \mid s\right)\right) G_{s s}\left(\rho^{*} \mid s\right)\right]\left[T(e, s)-\mathbb{E}\left(r \mid r>\rho^{*}, s\right)-\bar{\pi}\right]
\end{aligned}
$$

This term is unambiguously negative if the second term is positive, which can be ensured by the condition

$$
E\left(r \mid r>\rho^{*}, s\right)<-\int_{\rho^{*}}^{\bar{r}} r \frac{g_{s s}(r \mid s)}{G_{s s}\left(\rho^{*} \mid s\right)} d r \text { for } \rho^{*}<\bar{r} .
$$

Condition (A.9) essentially requires $G(. \mid$.) to be sufficiently convex. Note, however that it is a sufficient condition. $Q_{s s}<0$ will generally be satisfied for much weaker restrictions, e.g. if $c($.$) is sufficiently convex.$

Further, the cross-partial derivative is given by:

$$
Q_{e s}=-\frac{1-\delta}{\left[1-\delta G\left(\rho^{*} \mid s\right)\right]^{2}} c^{\prime \prime}(e+s)<0 .
$$

Under condition (A.9), all terms in $Q_{e e}$ and $Q_{s s}$ are negative. Therefore, $Q_{e e} Q_{s s}-Q_{e s}^{2}>0$ implying that the solution is a maximum.

\section{B Optimal Incentive Provision}

The Agent's Decision Problem. Differentiating the agent's objective function in $(I C)$ with respect to $e$ and $s$ gives:

$$
\begin{gathered}
f^{\prime}\left(e_{t}\right) \Delta b_{t}-c^{\prime}\left(e_{t}+s_{t}\right)=0 \\
\frac{\delta}{1-\delta} \int_{\underline{r}}^{\bar{r}} u_{t+1}\left(r, d_{t+1}\right) g_{s}(r \mid s)-c^{\prime}\left(e_{t}+s_{t}\right)=0 .
\end{gathered}
$$

Concavity of $f($.$) and convexity of c($.$) and G(. \mid$.$) ensure that these two equations define the unique global$ maximum $\left(e_{t}^{A}, s_{t}^{A}\right)$. The marginal effects of a change in $b_{t}$ on $e_{t}^{A}$ and $s_{t}^{A}$ can be obtained using the implicit 
function theorem. In particular, we have:

$$
\begin{gathered}
\frac{\partial e_{t}^{A}}{\partial b}=\frac{-f^{\prime}\left(e_{t}\right)\left[\frac{\delta}{1-\delta} \int_{\underline{r}}^{\bar{r}} u\left(r, d_{t+1}\right) g_{s s}\left(r \mid s_{t}\right) d r-c^{\prime \prime}\left(e_{t}+s_{t}\right)\right]}{\left[f^{\prime \prime}\left(e_{t}\right) b-c^{\prime \prime}\left(e_{t}+s_{t}\right)\right] \frac{\delta}{1-\delta} \int_{\underline{r}}^{\bar{r}} u\left(r, d_{t+1}\right) g_{s s}\left(r \mid s_{t}\right) d r-f^{\prime \prime}\left(e_{t}\right) \cdot b \cdot c^{\prime \prime}\left(e_{t}+s_{t}\right)}>0 . \\
\frac{\partial s_{t}^{A}}{\partial b}=\frac{-f^{\prime}\left(e_{t}\right) c^{\prime \prime}\left(e_{t}+s_{t}\right)}{\left[f^{\prime \prime}\left(e_{t}\right) b-c^{\prime \prime}\left(e_{t}+s_{t}\right)\right] \frac{\delta}{1-\delta} \int_{\underline{r}}^{\bar{r}} u\left(r, d_{t+1}\right) g_{s s}\left(r \mid s_{t}\right) d r-f^{\prime \prime}\left(e_{t}\right) \cdot b \cdot c^{\prime \prime}\left(e_{t}+s_{t}\right)}<0 . \\
\frac{\partial\left(e_{t}^{A}+s_{t}^{A}\right)}{\partial b}=\frac{-f^{\prime}\left(e_{t}\right)\left[\frac{\delta}{1-\delta} \int_{\underline{r}}^{\bar{r}} u\left(r, d_{t+1}\right) g_{s s}\left(r \mid s_{t}\right) d r\right]}{\left[f^{\prime \prime}\left(e_{t}\right) b-c^{\prime \prime}\left(e_{t}+s_{t}\right)\right] \frac{\delta}{1-\delta} \int_{\underline{r}}^{\bar{r}} u\left(r, d_{t+1}\right) g_{s s}\left(r \mid s_{t}\right) d r-f^{\prime \prime}\left(e_{t}\right) \cdot b \cdot c^{\prime \prime}\left(e_{t}+s_{t}\right)}>0 .
\end{gathered}
$$

\section{B.1 Constrained Second-Best}

Stationary Contracts under A2. The proof proceeds in the same way as the proof of lemma 1, but with the principal choosing $b$ instead of $(e, s)$ and having to respect $\left(I C_{e}\right)$ and $\left(I C_{s}^{\prime}\right)$ in addition to $(P C)$. Consider some date $t$ with $d_{t}=1$. The principal's and agent's payoffs are respectively given by:

$$
\begin{aligned}
& \pi_{t}=(1-\delta)\left[\underline{y}+f\left(e_{t}\right)\left(\Delta y-b_{t}\right)-w_{t}\right]+\delta \mathbb{E}_{r}\left[\pi_{t+1} \mid s_{t}\right] \\
& u_{t}=(1-\delta)\left[w_{t}+f\left(e_{t}\right) b_{t}-c\left(e_{t}+s_{t}\right)\right]+\delta \mathbb{E}_{r}\left[u_{t+1} \mid s_{t}\right]
\end{aligned}
$$

Total surplus is thus given by

$$
Q_{t}=(1-\delta)\left[\underline{y}+f\left(e_{t}\right) \Delta y-c\left(e_{t}+s_{t}\right)\right]+\delta \mathbb{E}_{r}\left[Q_{t+1} \mid s_{t}\right]
$$

Note that total surplus is independent of $r_{t}$ and that under A2, $e_{t}$ and $s_{t}$ are functions of $b_{t}$ only. Let $Q^{c S B}$ be the maximum surplus that can be generated when $d_{t}=1$ and let $b^{c S B}$ denote the associated bonus payment that implements $Q^{c S B}$. By A1, there is some $\rho^{c S B}<\bar{r}$ such that $\bar{\pi}+r>Q^{c S B}$ for all $r>\rho^{c S B}$. Hence, $(P C)$ implies that $d_{t}=0$ whenever $r_{t}>\rho^{c S B}$.

Under A2, when $\bar{\pi}+r_{t} \leq Q^{c S B}$, the principal maximizes her profits by offering a contract that implements $Q^{c S B}$ and pays the agent $r_{t}$. Such a contract pays the bonus $b^{c S B}$ and the fixed wage

$$
w_{t}=\frac{r_{t}}{1-\delta}-f\left(e\left(b^{c S B}\right)\right) b^{c S B}+c\left(e\left(b^{c S B}\right)+s\left(b^{c S B}\right)\right)-\frac{\mathbb{E}\left(r_{t+1}\right)}{1-\delta} .
$$

Offering such a contract whenever $d_{t}=1$ does not affect $\left(I C_{e}\right)$ or $\left(I C_{s}^{\prime}\right)$ in any prior period. It follows that $Q_{t+1}=Q^{c S B}$ if $r_{t+1} \leq \rho^{c S B}$ and $Q_{t+1}=\bar{\pi}+r_{t+1}$ if $r_{t+1}>\rho^{c S B}$. Thus, total surplus can be written as:

$Q_{t}=(1-\delta)\left[\underline{y}+f\left(e_{t}\right) \Delta y-c\left(e_{t}+s_{t}\right)\right]+\delta\left\{G\left(\rho^{c S B} \mid s_{t}\right) Q^{c S B}+\left[1-G\left(\rho^{c S B} \mid s_{t}\right)\right]\left[\bar{\pi}+\mathbb{E}_{r}\left(r_{t+1} \mid r_{t+1}>\rho^{c S B}, s_{t}\right)\right]\right\}$

Since $Q_{t}=Q^{c S B}$ as well, we have:

$Q_{t}=Q^{c S B}=\frac{1-\delta}{1-\delta G\left(\rho^{c S B} \mid s_{t}\right)}\left[y+f\left(e_{t}\right) \Delta y-c\left(e_{t}+s_{t}\right)\right]+\frac{\delta\left[1-G\left(\rho^{c S B} \mid s_{t}\right)\right]}{1-\delta G\left(\rho^{c S B} \mid s_{t}\right)}\left[\bar{\pi}+\mathbb{E}_{r}\left(r_{t+1} \mid r_{t+1}>\rho^{c S B}, s_{t}\right)\right]$.

Thus, at any date $t$ with $r_{t} \leq \rho^{c S B}$, the principal faces the same maximization problem and hence always chooses the bonus payment $b^{c S B}$ implementing the stationary effort profile $\left(e^{c S B}, s^{c S B}\right)$.

Distorted Search Incentives. The efficient level of $s$ given $e, \widehat{s}^{S I}(e)$, is implicitly defined by

$$
\frac{\delta G_{s}\left(\rho^{*} \mid s\right)}{1-\delta G\left(\rho^{*} \mid s\right)}\left[T(e, s)-\mathbb{E}_{r}\left(r \mid r>\rho^{*}, s\right)-\bar{\pi}\right]+\frac{\delta}{1-\delta} \int_{\rho^{*}}^{\bar{r}} r g_{s}(r \mid s) d r=c^{\prime}(e+s)
$$


Further, under A2, the agent's privately optimal level of $s$ given $e, \widehat{s}^{A}(e)$, is implicitly defined by $\left(I C_{s}^{\prime}\right)$ :

$$
\frac{\delta}{1-\delta} \int_{\underline{r}}^{\bar{r}} r g_{s}(r \mid s)=c^{\prime}(e+s) \text {. }
$$

The RHS of these two equations is identical and increasing in $e$ and $s$. Hence, $\widehat{s}^{A}(e)>\widehat{s}^{S I}(e)$ if and only if

$$
\frac{\delta}{1-\delta} \int_{\underline{r}}^{\bar{r}} r g_{s}(r \mid s)>\frac{\delta G_{s}\left(\rho^{*} \mid s\right)}{1-\delta G\left(\rho^{*} \mid s\right)}\left[T(e, s)-\mathbb{E}_{r}\left(r \mid r>\rho^{*}, s\right)-\bar{\pi}\right]+\frac{\delta}{1-\delta} \int_{\rho^{*}}^{\bar{r}} r g_{s}(r \mid s) d r .
$$

The RHS of (B.2) can alternatively be written as

$$
\frac{\delta G_{s}\left(\rho^{*} \mid s\right)}{1-\delta G\left(\rho^{*} \mid s\right)}\left[T(e, s)-\mathbb{E}_{r}\left(r \mid r>\rho^{*}, s\right)-\bar{\pi}\right]+\frac{\delta\left[1-G\left(\rho^{*} \mid s\right)\right]}{1-\delta} \frac{\partial \mathbb{E}\left(r \mid r>\rho^{*}, s\right)}{\partial s},
$$

while its LHS can be rewritten as:

$$
\frac{\delta\left[1-G\left(\rho^{*} \mid s\right)\right]}{1-\delta} \frac{\partial \mathbb{E}\left(r \mid r>\rho^{*}, s\right)}{\partial s}+\frac{\delta G_{s}\left(\rho^{*} \mid s\right)}{1-\delta}\left[\mathbb{E}\left(r \mid r \leq \rho^{*}, s\right)-\mathbb{E}\left(r \mid r>\rho^{*}, s\right)\right]+\frac{\delta G\left(\rho^{*} \mid s\right)}{1-\delta} \frac{\partial \mathbb{E}\left(r \mid r \leq \rho^{*}, s\right)}{\partial s} .
$$

Subtracting (B.3) from (B.4) yields after some algebra:

$$
\delta G_{s}\left(\rho^{*} \mid s\right)\left\{\frac{T(e, s)-\bar{\pi}}{1-\delta G\left(\rho^{*} \mid s\right)}+\frac{\delta\left[1-G\left(\rho^{*} \mid s\right)\right]}{1-\delta G\left(\rho^{*} \mid s\right)} \frac{\mathbb{E}\left(r \mid r>\rho^{*}, s\right)}{1-\delta}-\frac{\mathbb{E}\left(r \mid r \leq \rho^{*}, s\right)}{1-\delta}\right\}-\frac{\delta G\left(\rho^{*} \mid s\right)}{1-\delta} \frac{\partial \mathbb{E}\left(r \mid r \leq \rho^{*}, s\right)}{\partial s} .
$$

The second part of this expression is clearly negative. Further, for any $(e, s),(P C)$ implies $Q(e, s)>\bar{\pi}+$ $\mathbb{E}\left(r \mid r \leq \rho^{*}, s\right)$, which, using $\left(S I C_{s}\right)$, implies

$$
\frac{1-\delta}{1-\delta G\left(\rho^{*} \mid s\right)} T(e, s)+\frac{\delta\left[1-G\left(\rho^{*} \mid s\right)\right]}{1-\delta G\left(\rho^{*} \mid s\right)} \mathbb{E}\left(r \mid r>\rho^{*}, s\right)-\mathbb{E}\left(r \mid r \leq \rho^{*}, s\right) \geq 0 .
$$

(B.6) implies that the first part of (B.5) is negative as well, proving that $\widehat{s}^{A}(e)>\widehat{s}^{S I}(e)$ for any $(e, s)$ for which $(P C)$ is satisfied.

Proof of Proposition 1. The fact that $\widehat{s}^{A}(e)>\widehat{s}^{A}(e)$ for any $(e, s)$ for which $(P C)$ is satisfied implies $\widehat{s}^{A}\left(e^{S I}\right)>$ $\widehat{s}^{S I}\left(e^{S I}\right)=s^{S I}$. Proposition 1 follows immediately.

Proof of Lemma 2. The first-order condition of the principal's problem is given by

$$
Q_{e} \frac{\partial e^{A}}{\partial b}+Q_{s} \frac{\partial s^{A}}{\partial b}=0
$$

Since $\widehat{s}^{A}(e)>\widehat{s}^{S I}(e), Q_{s}<0$. Together with (1), this implies that $Q_{e}<0$ in (B.7). From $\left(S I C_{e}\right)$ and $\left(I C_{e}\right)$ it then follows that $b^{c S B}>\Delta y$.

\section{B.2 Efficiency Wages}

Proof of Proposition 2. By $\left(S I C_{s}\right)$ and $\left(I C_{s}\right)\left(e^{A}, s^{A}\right)=\left(e^{S I}, s^{S I}\right)$ only if

$$
\frac{\delta G_{s}\left(\rho^{*} \mid s\right)}{1-\delta G\left(\rho^{*} \mid s\right)}\left[T(e, s)-\mathbb{E}_{r}\left(r \mid r>\rho^{*}, s\right)-\bar{\pi}\right]+\frac{\delta}{1-\delta} \int_{\rho^{*}}^{\bar{r}} r g_{s}(r \mid s) d r=\frac{\delta}{1-\delta} \int_{\underline{r}}^{\bar{r}} u_{t+1}\left(r, d_{t+1}\right) g_{s}(r \mid s) d r
$$

Under $(P C)$, this is equivalent to

$$
\frac{\delta G_{s}\left(\rho^{*} \mid s\right)}{1-\delta G\left(\rho^{*} \mid s\right)}\left[T(e, s)-\mathbb{E}_{r}\left(r \mid r>\rho^{*}, s\right)-\bar{\pi}\right]=\frac{\delta}{1-\delta} \int_{\underline{r}}^{\rho^{*}} u_{t+1}(r, 1) g_{s}(r \mid s) d r
$$


By $(P C)$, this equality can only hold if $u_{t+1}(r, 1)=\widetilde{u}$ for some constant $\widetilde{u}$ for all $r \in\left[\underline{r}, \rho^{*}\right]$. Setting $u_{t+1}(r, 1)=\widetilde{u}$ gives

$$
\frac{\delta G_{s}\left(\rho^{*} \mid s\right)}{1-\delta G\left(\rho^{*} \mid s\right)}\left[T(e, s)-\mathbb{E}_{r}\left(r \mid r>\rho^{*}, s\right)-\bar{\pi}\right]=\frac{\delta G\left(\rho^{*} \mid s\right)}{1-\delta} \widetilde{u} .
$$

After some reshuffling, we finally get

$$
\widetilde{u}=Q(e, s)-\bar{\pi}
$$

By (3), this is equivalent to

$$
\widetilde{u}=\phi\left(\rho^{*}, s\right)[T(e, s)-\bar{\pi}]+\left(1-\phi\left(\rho^{*}, s\right)\right)\left[\mathbb{E}_{r}\left(r \mid r>\rho^{*}, s\right)\right]
$$

which shows that under efficient effort incentives, the agent must earn $T(e, s)-\bar{\pi}$ per period in which he trades with the principal.

Marginal Effects of $r_{0}$. When the principal implements the efficiency wage threshold $r_{0}$, the agent's optimal decision $\left(e^{A}, s^{A}\right)$ is defined by $\left(I C_{e}\right)$ and $\left(I C_{s}^{\prime \prime}\right)$. Thus, the marginal effect of $r_{0}$ on $e^{A}$ and $s^{A}$ can be obtained using the implicit function theorem. In particular, we have:

$$
\begin{gathered}
\frac{\partial e^{A}}{\partial r_{0}}=\frac{-\frac{\delta}{1-\delta} G_{s}\left(r_{0} \mid s\right) c^{\prime \prime}(e+s)}{\left[f^{\prime \prime}(e) b-c^{\prime \prime}(e+s)\right] \frac{\delta}{1-\delta} \int_{\underline{r}}^{\bar{r}} u\left(r, d_{t+1}\right) g_{s s}(r \mid s) d r-f^{\prime \prime}(e) \cdot b \cdot c^{\prime \prime}(e+s)}>0, \\
\frac{\partial s^{A}}{\partial r_{0}}=\frac{-\frac{\delta}{1-\delta} G_{s}\left(r_{0} \mid s\right)\left[f^{\prime \prime}(e) b-c^{\prime \prime}(e+s)\right]}{\left[f^{\prime \prime}(e) b-c^{\prime \prime}(e+s)\right] \frac{\delta}{1-\delta} \int_{\underline{r}}^{\bar{r}} u\left(r, d_{t+1}\right) g_{s s}(r \mid s) d r-f^{\prime \prime}\left(e_{t}\right) \cdot b \cdot c^{\prime \prime}(e+s)}<0, \\
\frac{\partial\left(e^{A}+s^{A}\right)}{\partial r_{0}}=\frac{-\frac{\delta}{1-\delta} G_{s}\left(r_{0} \mid s\right) f^{\prime \prime}(e) b}{\left[f^{\prime \prime}(e) b-c^{\prime \prime}(e+s)\right] \frac{\delta}{1-\delta} \int_{\underline{r}}^{\bar{r}} u\left(r, d_{t+1}\right) g_{s s}(r \mid s) d r-f^{\prime \prime}(e) \cdot b \cdot c^{\prime \prime}(e+s)}<0,
\end{gathered}
$$

where $\frac{\delta}{1-\delta} G_{s}\left(r_{0} \mid s\right)$ is the partial derivative of the LHS of $\left(I C_{s}^{\prime \prime}\right)$ with respect to $r_{0}$.

Proof of Lemma 3. Fix $r_{0} \in\left[\underline{r}, \rho^{*}\right)$ and subtract the LHS of $\left(I C_{s}^{\prime \prime}\right)$ from the LHS of $\left(S I C_{s}\right)$, giving

$$
\frac{\delta G_{s}\left(\rho^{*} \mid s\right)}{1-\delta G\left(\rho^{*} \mid s\right)}\left[T(e, s)-\mathbb{E}_{r}\left(r \mid r>\rho^{*}, s\right)-\bar{\pi}\right]-\frac{\delta}{1-\delta}\left[G_{s}\left(r_{0} \mid s\right) r_{0}-G_{s}\left(\rho^{*} \mid s\right) \mathbb{E}_{r}\left(r \mid r>\rho^{*}, s\right)+\int_{r_{0}}^{\rho^{*}} r g_{s}(r \mid s) d r\right] .
$$

Noting that

$$
G_{s}\left(r_{0} \mid s\right) r_{0}+\int_{r_{0}}^{\rho^{*}} r g_{s}(r \mid s) d r=G\left(\rho^{*} \mid s\right) \frac{\partial \mathbb{E}\left[u(r, 1) \mid r \leq \rho^{*}, s\right]}{\partial s}+G_{s}\left(\rho^{*} \mid s\right) \mathbb{E}\left[u(r, 1) \mid r \leq \rho^{*}, s\right],
$$

after some algebra, we get

$$
\frac{\delta}{1-\delta}\left\{G_{s}\left(\rho^{*} \mid s\right)\left[T(e, s)-\bar{r}-\mathbb{E}\left[u(r, 1) \mid r \leq \rho^{*}, s\right]\right]-G\left(\rho^{*} \mid s\right) \frac{\partial \mathbb{E}\left[u(r, 1) \mid r \leq \rho^{*}, s\right]}{\partial s}\right\} .
$$

Under $(P C)$, this term is unambiguously negative, implying that $\widehat{s}^{A}(e)>\widehat{s}^{S I}(e)$ for any $r_{0} \in\left[\underline{r}, \rho^{*}\right]$. Differentiating the principal's profit function with respect to $b$ yields the first-order condition:

$$
Q_{e} \frac{\partial e^{A}}{\partial b}+Q_{s} \frac{\partial s^{A}}{\partial b}=0
$$

Since $\widehat{s}^{A}(e)>\widehat{s}^{S I}(e), Q_{s}<0$ and thus $Q_{e}<0$ in the first-order condition for any $r_{0} \in\left[\underline{r}, \rho^{*}\right]$. From $\left(S I C_{e}\right)$ and $\left(I C_{e}\right)$ it then follows that $b\left(r_{0}\right)>\Delta y$, which in turn implies $Q\left(r_{0}\right)<Q^{S I}$ for any $r_{0} \in\left[\underline{r}, \rho^{*}\right)$.

Proof of Lemma 4. By definition, $Q\left(\rho^{*}\right)-\rho^{*}=\bar{\pi}$. Hence, $Q\left(\rho^{*}\right)-\rho^{*} \geq Q^{c S B}-\underline{r}$ if and only if $Q^{c S B}-\underline{r} \leq \pi$. 
Concavity of $Q\left(r_{0}\right)$. As proven in the text, $Q^{\prime}\left(r_{0}\right)>0$ for all $r_{0} \in\left[\bar{r}, \rho^{*}\right)$ and by proposition $2, Q\left(r_{0}\right)<Q\left(\rho^{*}\right)$ for any $r_{0} \neq \rho^{*}$. Further, since $f(e)$ and $G(r \mid s)$ are continuously differentiable, $Q\left(r_{0}\right)$ is also continuous and differentiable on $\left[\bar{r}, \rho^{*}\right]$. Therefore, $Q^{\prime}\left(\rho^{*}\right)=0$. Finally, since $\frac{\partial e^{A}}{\partial r_{0}}$ and $\left|\frac{\partial s^{A}}{\partial r_{0}}\right|$ are finite for any $\left(\underline{r}, \rho^{*}\right]$, so must be $Q^{\prime}\left(r_{0}\right)$. It follows that $Q\left(r_{0}\right)$ is concave on $\left[\bar{r}, \rho^{*}\right]$.

Proof of Lemma 5. Since $Q^{c S B}-\underline{r}$, under A2, $d_{t}=0$ for all $r_{t} \in[\underline{r}, \bar{r}]$. But since $Q^{S I}-\rho^{*}=Q\left(\rho^{*}\right)-\rho^{*}>\bar{\pi}$ and because $\rho^{*}$ maximizes $\rho^{*}$, there exists $r_{0}^{\prime} \in\left(\underline{r}, \rho^{*}\right)$ such that $Q\left(r_{0}^{\prime}\right)-r_{0}^{\prime} \geq Q^{c S B}-\underline{r}$. Hence, there exists a PPE with $r_{0}=r_{0}^{\prime}$ in which $d_{t}=1$ for $r_{t} \leq \rho\left(r_{0}^{\prime}\right)$.

Proof of Proposition 3. If $Q^{\prime}(\underline{r}) \geq 1$, then, there si some $\epsilon>0$ such that $(E C)$ holds for $r_{0}=\underline{r}+\epsilon$. If $Q^{\prime}(\underline{r})<1$, then, by concavity of $Q\left(r_{0}\right), Q\left(r_{0}\right)-Q^{c S B}<r_{0}-\underline{r}$ for all $r_{0} \in\left(\underline{r}, \rho^{*}\right]$, proving that the condition is both necessary and sufficient.

\section{B.3 Equilibrium Selection}

Proof of Lemma 6. By definition, $\widehat{r}$ maximizes $Q\left(r_{0}\right)-r_{0}$. Hence, if $r_{1} \leq \widehat{r}, r_{0}^{*}\left(r_{1}\right)=\widehat{r}$. But if, $r_{1}>\widehat{r},(P C)$ precludes implementing $\widehat{r}$. Since $r_{1}$ must be paid anyways and since $Q\left(r_{0}\right)$ is strictly increasing for $r_{0} \leq \rho^{*}$, profits are maximized by setting $r_{0}=r_{1}$. However, when $r_{1}>r_{0}^{\max },(E C)$ precludes paying $r_{1}$ as an efficiency wage. Again, since $Q^{\prime}\left(r_{0}\right)>0$, profits are maximized by implementing the largest efficiency wage that is self-enforcing, hence $r_{0}=r_{0}^{\max }$ if $r_{1}>r_{0}^{\max }$. Finally, if $r_{1}>\rho\left(r_{0}^{\max }\right)$, no contract will be offered.

\section{Extensions}

Proof of Lemma 7. I begin with the first part of the lemma. If the principal can commit to paying the efficiency wage $r_{0}$, her problem is equivalent to $(M 1)$, but without the need to respect $(E C)$. Hence, since $\widehat{r}$ maximizes $Q\left(r_{0}\right)-r_{0}, r_{0}^{c}=\widehat{r}$ if $r_{1} \leq \widehat{r}$. If $r_{1}>\widehat{r_{0}}$, since $Q\left(r_{0}\right)$ is increasing in $r_{0}$ and as $r_{1}$ has to be paid anyways, $r_{0}^{c}=r_{1}$. In contrast to lemma $6, r_{0}^{c}=r_{1}$ even if $r_{1}>r_{0}^{\max }$, because $(E C)$ need not be satisfied. Finally, if $r_{1}>\rho^{*}$, the principal will offer no contract, since any contract would yield her profits smaller than $\bar{\pi}$.

Proof of Lemma 8. By $(D E)$, if $b^{c S B}>b^{\max }, b^{I C}<b^{c S B}$. Hence at $b=b^{I C}$ :

$$
\left.\frac{\partial Q(e, s)}{\partial b}\right|_{b=b^{I C}}=Q_{e} \frac{\partial e}{\partial b}+Q_{s} \frac{\partial s}{\partial b}>0 .
$$

Thus, the principal will set $b^{I C}$ equal to the largest level possible. By $(D E), b^{I C}=b^{\text {max }}$. Further, $Q\left(b^{I C}\right)<$ $Q^{c S B}$, since by $b^{I C}<b^{c S B}$ and the definition of $b^{c S B}$.

Marginal Benefit of $r_{0}$ under Relational Contracts. When $b^{c S B}>b^{\text {max }}$, we can have one of two cases. Either $b^{I C} \leq \Delta y$ or $b^{I C}>\Delta y$. In the former case, $Q_{e}>0$ and $Q_{s}<0$. Since $r_{0}$ increases $e$ and decreases $s$, we have at $b^{I C}$ :

$$
\frac{\partial Q(e, s)}{\partial r_{0}}=Q_{e} \frac{\partial e}{\partial r_{0}}+Q_{s} \frac{\partial s}{\partial r_{0}}>0 .
$$

If $b^{I C}>\Delta y$, then at $b=b^{I C}$,

$$
-Q_{e} \frac{\partial e}{\partial b}<Q_{s} \frac{\partial s}{\partial b},
$$

with $Q_{s}<0$ and $Q_{e}<0$. Hence:

$$
\frac{Q_{s}}{Q_{e}}>-\frac{\frac{\partial e}{\partial b}}{\frac{\partial s}{\partial b}} .
$$

Since

$$
-\frac{\frac{\partial e}{\partial r_{0}}}{\frac{\partial s}{\partial r_{0}}}<-\frac{\frac{\partial e}{\partial b}}{\frac{\partial s}{\partial b}},
$$


it follows that

$$
\frac{\partial Q(e, s)}{\partial r_{0}}=Q_{e} \frac{\partial e}{\partial r_{0}}+Q_{s} \frac{\partial s}{\partial r_{0}}>0
$$

Proof of Lemma 9. Adding $b^{\text {max }}$ and $-b^{\text {min }}$ gives:

$$
\Delta b^{\max } \equiv \frac{\delta}{1-\delta} G(\rho \mid s)[Q(e, s)-\mathbb{E}(r \mid r \leq \rho, s)-\bar{\pi}]
$$

Differentiating this expression with respect to $r_{0}$ yields:

$$
\begin{aligned}
\frac{\partial \Delta b^{\max }}{\partial r_{0}} & =\delta g(\rho \mid s)[Q(e, s)-\mathbb{E}(r \mid r \leq \rho, s)-\bar{\pi}] \frac{\partial \rho}{\partial Q} \frac{\partial Q}{\partial r_{0}} \\
& +\delta G_{s}(\rho \mid s)[Q(e, s)-\mathbb{E}(r \mid r \leq \rho, s)-\bar{\pi}] \frac{\partial s}{\partial r_{0}} \\
& +\delta G(\rho \mid s)\left[\frac{\partial Q}{\partial r_{0}}-\frac{\partial \mathbb{E}(r \mid r \leq \rho, s)}{\partial s} \frac{\partial s}{\partial r_{0}}-\frac{\partial \mathbb{E}(r \mid r \leq \rho, s)}{\partial \rho} \frac{\partial \rho}{\partial Q} \frac{\partial Q}{\partial r_{0}}\right]
\end{aligned}
$$

Using

$$
\begin{aligned}
\frac{\partial \mathbb{E}(r \mid r \leq \rho, s)}{\partial \rho} & =\frac{g(\rho \mid s)}{G(\rho \mid s)}[\rho-\mathbb{E}(r \mid r \leq \rho, s)], \\
\frac{\partial \rho}{\partial Q} & =\frac{1}{1-\delta G(\rho \mid s)},
\end{aligned}
$$

and canceling terms gives

$$
\begin{aligned}
\frac{\partial \Delta b^{\max }}{\partial r_{0}} & =\delta G_{s}(\rho \mid s)[Q(e, s)-\mathbb{E}(r \mid r \leq \rho, s)-\bar{\pi}] \frac{\partial s}{\partial r_{0}} \\
& +\delta G(\rho \mid s)\left[\frac{\partial Q}{\partial r_{0}}-\frac{\partial \mathbb{E}(r \mid r \leq \rho, s)}{\partial s} \frac{\partial s}{\partial r_{0}}\right]
\end{aligned}
$$

By $(P C), Q(e, s)>\mathbb{E}(r \mid r \leq \rho, s)+\bar{\pi}$. Further,

$$
\frac{\partial \mathbb{E}(r \mid r \leq \rho, s)}{\partial s}>0
$$

It follows that

$$
\frac{\partial \Delta b^{\max }}{\partial r_{0}}>0
$$

The Agent's Incentive Compatibility Constraints under Limited Liability. Under limited liability and if the principal offers a stationary contract, the agent's payoff at every date $t$ with $d_{t}=1$ is

$$
\rho^{\prime}=\frac{1-\delta}{1-\delta G\left(\rho^{\prime} \mid s\right)}[f(e) b-c(e+s)]+\frac{\delta}{1-\delta G\left(\rho^{\prime} \mid s\right)} \int_{\rho^{\prime}}^{\bar{r}} r g(r \mid s) d r
$$

Since $\rho^{\prime}$ is implicitly defined, define

$$
G\left(e, s ; \rho^{\prime}, b\right)=\frac{1-\delta}{1-\delta G\left(\rho^{\prime} \mid s\right)}[f(e) b-c(e+s)]+\frac{\delta}{1-\delta G\left(\rho^{\prime} \mid s\right)} \int_{\rho^{\prime}}^{\bar{r}} r g(r \mid s) d r-\rho^{\prime}=0 .
$$

Differentiating this expression with respect to $\rho^{\prime}$ gives:

$$
\frac{\partial G\left(e, s ; \rho^{\prime}, b\right)}{\partial \rho^{\prime}}=\frac{\delta g\left(\rho^{\prime} \mid s\right)}{1-\delta G\left(\rho^{\prime} \mid s\right)} \rho^{\prime}-\frac{\delta g\left(\rho^{\prime} \mid s\right)}{1-\delta G\left(\rho^{\prime} \mid s\right)} \rho^{\prime}-1=-1
$$

Hence, by the implicit function theorem, the derivative of $\rho^{\prime}$ with respect to $e$ and $s$ is just equal to the the 
derivative of the RHS of (C.2). Hence, the first-order conditions of the agent's problem under limited liability are identical to $\left(I C_{e}\right)$ and $\left(I C_{s}^{\prime \prime}\right)$ with $r_{0}=\rho^{\prime}$.

Differentiating (C.2) with respect to $b$ gives:

$$
\frac{\partial \rho^{\prime}}{\partial b}=\frac{\partial \rho^{\prime}}{\partial e} \frac{\partial e}{\partial b}+\frac{\partial \rho^{\prime}}{\partial s} \frac{\partial s}{\partial b}+\frac{\partial \rho^{\prime}}{\partial b}
$$

The first two terms of this expression are equal to zero, hence:

$$
\frac{\partial \rho^{\prime}}{\partial b}=\frac{\partial \rho^{\prime}}{\partial b}=\frac{1-\delta}{1-\delta G\left(\rho^{\prime} \mid s\right)} f(e)>0 .
$$

Proof of Lemma 10. The proof proceeds by showing that there is no $r_{t}$ for which the principal could raise her profits by deviating to a contract offer different from the one specified in lemma 10.

Recall that $b_{0}^{l}$ denotes the bonus that solves the principal's first-order condition (6.3). Hence, it represents the bonus that maximizes the principal's profits conditional on $d_{t}=1$ and given the continuation play specified in lemma 10. Further, given continuation play, the agent's payoff when $b=b_{0}^{l}$ is equal to $r_{0}^{l}$. Thus, whenever $r_{t} \leq r_{0}^{l}$, the agent will accept the contract $b=b_{0}^{l}$ and, by construction, there is no other bonus that yields the principal higher profits. Further, since $\left(I C_{e}\right)$ and $\left(I C_{s}^{\prime \prime}\right)$ have a unique solution, the agent chooses the same effort profile $\left(e_{0}^{l}, s_{0}^{l}\right)$ whenever $b=b_{0}^{l}$. It follows that the principal's profit and the agent's payoff will be the same whenever $r_{t} \leq r_{0}^{l}$.

When $r_{t} \in\left(r_{0}^{l}, \rho^{l}\right]$, the principal must offer a contract that yields the agent a higher payoff than $r_{0}^{l}$. This can be either done by raising the fixed wage component $w_{t}$ or by offering a higher bonus payment. For $r>r_{0}^{l}$ and given $b=b_{0}^{l}$, the fixed wage that the principal must offer to satisfy the agent's participation constraint is

$$
w(r)=\frac{1-\delta G\left(\rho^{l} \mid s\right)}{1-\delta}\left(r-r_{0}^{l}\right)
$$

Since $w(r)$ is a mere transfer, it reduces the principal's profits by exactly $w(r)$. Alternatively, the principal can raise the bonus to meet the agent's participation constraint. Let $b^{l}(r)>b_{0}^{l}$ denote the bonus payment such that $u=r$. Under limited liability, the principal will offer a contract only if $b^{l}<\Delta y$. However, since total surplus is increasing for all $b \leq \Delta y$, raising $b$ above $b_{0}^{l}$ increases total surplus. Let $\Delta Q(r)>0$ denote the associated increase in total surplus. The principal's costs of raising $b$ from $b_{0}^{l}$ to $b^{l}(r)$ are hence equal to $\left(r-r_{0}^{l}\right)-\Delta Q(r)>0$, which is strictly smaller than $\left(r-r_{0}^{l}\right)$. Hence, the principal can raise the agent's payoff more cheaply by increasing $b$ instead of $w$. Further, by construction, any increase of $b$ above $b_{0}^{l}$ reduces the principal's profits. Thus, the contract that maximizes the principal's profits for any $r_{t}>r_{0}^{l}$ is $b^{l}\left(r_{t}\right)$. Since $b^{l}(r)$ is increasing in $r$, there will be some $\rho^{l}$ such that for all $r>\rho^{l}$ the profit-maximizing contract offer that satisfies the agent's participation constraint yields the principal profits smaller than $\bar{\pi}$. Hence, $\rho^{l}$ constitutes the equilibrium separation threshold. Finally, by (1), $e^{l}\left(s^{l}\right)$ is increasing (decreasing) in $b^{l}(r)$.

\section{Endogenizing the Set of Outside Options}

Throughout the analysis, a draw of the outside option $r \in[\underline{r}, \bar{r}]$ was interpreted as the discounted average per-period payoff implied by accepting the job behind the offer $r$. Thus, $r$ reflected the value of a job in the supergame rather than the maximum wage the alternative employer could offer. In this section, I delineate how the interval $[\underline{r}, \bar{r}]$ can be endogenized within a model of a labor market with a continuum of jobs in which the agent can potentially work that differ with respect to the agent's productivity in the job.

Suppose that there is a mass $J$ of jobs in which the agent can potentially work. Jobs are indexed by $j \in[0, J]$. Every job $j$ is associated with a principal and represented by a moral hazard problem of the type 
described in section 3. Thus, the agent chooses work and search effort in every period, irrespective of which job he is currently working in. However, jobs or principals differ with respect to their productivity. Let $Q(j ; \underline{r}, \bar{r})$ denote the equilibrium surplus that the agent can generate in job $j$ given arbitrary values for $\underline{r}$ and $\bar{r}$. I assume that $Q_{j}(j ; \underline{r}, \bar{r})>0$, i.e. jobs with a higher productivity are represented by higher indexes. Differences in productivity could for instance be generated by differences in the production technology, i.e. jobs might differ with respect to $f_{i}(e), \underline{y}_{i}$ or $\Delta y_{i}$. Principal $j$ 's maximum willingness-to-pay for the agent's services is therefore given by $\omega_{j}=Q(j, \underline{r}, \bar{r})-\bar{\pi}$. Thus, every range of outside options $[\underline{r}, \bar{r}]$ generates a range $[\underline{\omega}, \bar{\omega}]$, where $\underline{\omega}$ and $\bar{\omega}$ denote the lowest and highest willingness-to-pay for the agent's services over all firms, respectively. The goal of this section is to derive an equilibrium in which the range $[\underline{r}, \bar{r}]$ coincides with $[\underline{\omega}, \bar{\omega}]$.

Let $j_{t}$ denote the firm that employed the agent at date $t-1$ and suppose that at the start of period $t$, the agent samples $N_{t}$ new jobs from the population $[0, J]$ such that he entertains $N_{t}+1$ job offers at the start of date $t$. Let $\Omega_{t}$ denote the set of willingnesses to pay of all new firms sampled at date $t$ and define $\omega_{t}^{\max } \equiv \max \left\{\omega_{j}\right\}_{\omega_{j} \in \Omega_{t}}$. Assuming that firms engage in Bertrand competition for the agent, his outside option when staying with firm $j_{t}$ (i.e. if $\omega_{j_{t}} \geq \omega_{t}^{\max }$ ) is $\omega_{t}^{\max }$. By contrast, if he switches firms (i.e. if $\omega_{j_{t}}<\omega_{t}^{\max }$ ), his continuation payoff is bounded by $\omega_{t}^{\max }$. In particular, even though firms engage in Bertrand competition, the agent's continuation payoff may well be larger than his second-highest offer, because his new employer might prefer to pay him an efficiency wage. Thus, within this setting, the range of the agent's outside options is given by firms' willingnesses to pay for the agent's services, $[\underline{\omega}, \bar{\omega}]$ However, recall that this range depends on the specification of $\underline{r}$ and $\bar{r}$. In equilibrium, the range of the agent's potential outside options must therefore be identical to the range of willingnesses-to-pay that it generates, i.e. $[\underline{r}, \bar{r}]=[\underline{\omega}, \bar{\omega}]$.

Finally, to derive the relationship between search effort and the distribution of outside options, specified in section 3, assume that in the sketched model, the expected number of jobs sampled at $t$ is increasing in $s_{t-1}$. In that case, the implied distribution over the agent's outside option is equivalent to the formulation from section 3 , because a higher level of search induces a more favorable distribution over the best job offer, the agent will entertain in the next period.

The model sketched in this section indicates why it is difficult to assess the impact of the discount factor onto the contracting problem. Since changes in the discount factor will affect the incentive structure and hence the productivity within a given job, it will also influence the set of outside options. Yet, even the effects of changes in the discount factor on the productivity of a single employment relationship is ambiguous. On the one hand, a higher discount factor raises the agent's search incentives, thereby aggravating the incentive problem. On the other hand, it also raises the social benefits from search, thereby raising surplus within a given employment relationship. 


\section{References}

Abreu, D., D. Pearce, And E. Stacchetti (1990): "Toward a Theory of Discounted Repeated Games with Imperfect Monitoring," Econometrica, 58(5), 1041-1063.

Baker, G., R. Gibbons, And K. J. Murphy (2002): "Relational Contracts and the Theory of the Firm," Quarterly Journal of Economics, pp. 39-84.

Bebchuk, L. A., And J. M. Fried (2003): "Executive Compensation as an Agency Problem," Journal of Economic Perspectives, 71, 92.

BÉnabou, R., And J. Tirole (2013): "Bonus Culture: Competitive Pay, Screening, and Multitasking," Discussion paper, National Bureau of Economic Research.

Berman, E., J. Bound, AND S. Machin (1998): "Implications of Skill-Biased Technological Change: International Evidence," The Quarterly journal of economics, 113(4), 1245-1279.

Bertrand, M., And S. Mullainathan (2001): "Are CEOs rewarded for luck? The ones without principals are," Quarterly Journal of Economics, pp. 901-932.

BoArd, S., AND M. Meyer-TER Vehn (2013): "Relational contracts in competitive labor markets," .

Brown, M., AND J. S. HeYwood (2002): Paying for performance: An international comparison. ME Sharpe.

Bull, C. (1987): "The Existence of Self-Enforcing Implicit Contracts," Quarterly Journal of Economics, 102(1), $147-159$.

Cahuc, P., F. Postel-Vinay, And J.-M. Robin (2006): "Wage bargaining with on-the-job search: Theory and evidence," Econometrica, 74(2), 323-364.

Christensen, B. J., R. Lentz, D. T. Mortensen, G. R. Neumann, and A. Werwatz (2005): "On-theJob Search and the Wage Distribution," Journal of Labor Economics, 23(1), 31-58.

Fallick, B., AND C. A. Fleischman (2004): Employer-to-employer flows in the US labor market: The complete picture of gross worker flows, vol. 4. Division of Research \& Statistics and Monetary Affairs, Federal Reserve Board.

FARBer, H. S. (1999): "Mobility and stability: The dynamics of job change in labor markets," Handbook of labor economics, 3, 2439-2483.

FRYDMAN, C. (2007): "Rising through the ranks. the evolution of the market for corporate executives, 19362003," Discussion paper, working paper, MIT.

Frydman, C., AND R. E. SAKs (2010): "Executive compensation: A new view from a long-term perspective, 1936-2005," Review of Financial Studies, p. hhp120.

Fudenberg, D., D. Levine, And E. Maskin (1994): "The folk theorem with imperfect public information," Econometrica: Journal of the Econometric Society, pp. 997-1039.

Giannetti, M. (2011): "Serial CEO incentives and the structure of managerial contracts," Journal of Financial Intermediation, 20(4), 633-662.

Gibbons, R. (2005): "Incentives between firms (and within)," Management Science, 51(1), 2-17.

Holmström, B., AND P. Milgrom (1991): "Multitask principal-agent analyses: Incentive contracts, asset ownership, and job design," JL Econ. $\& 3$ Org., 7, 24. 
Holzner, C. (2011): "Optimal Wage Policy with Endogenous Search Intensity,” .

Jaeger, D. A., And A. H. Stevens (1999): "Is Job Stability in the United States Falling? Reconciling Trends in the Current Population Survey and Panel Study of Income Dynamics," Journal of Labor Economics, 17(S4), S1-S28.

Katz, L. F., AND H. Autor, DAvid (1999): "Changes in the wage structure and earnings inequality," Handbook of Labor Economics, 3, 1463-1555.

LAzear, E. P. (1998): "Personnel Economics," MIT Press Books, 1.

Lazear, E. P., And K. L. Shaw (2007): "Personnel Economics: The Economist's View of Human Resources," The Journal of Economic Perspectives, pp. 91-114.

Lemieux, T., W. B. Macleod, And D. Parent (2009): "Performance Pay and Wage Inequality," The Quarterly Journal of Economics, 124(1), 1-49.

LENTz, R. (2010): "Sorting by search intensity," Journal of Economic Theory, 145(4), 1436-1452.

(2014): "Optimal Employment Contracts with Hidden Search," .

Levin, J. (2003): "Relational Incentive Contracts," American Economic Review, 93(3), 835-857.

LisE, J. (2013): "On-the-job search and precautionary savings," The Review of Economic Studies, 80(3), 10861113.

MacLeod, W. B., And J. M. Malcomson (1989): "Implicit Contracts, Incentive Compatibility, and Involuntary Unemployment," Econometrica, 57(2), 447-480.

(1998): "Motivation and markets," American Economic Review, pp. 388-411.

Mailath, G. J., And L. Samuelson (2006): Repeated Games and Reputations: Long-run Relationships. Oxford University Press.

Malcomson, J. A. (2012): "Relational Incentive Contracts," Handbook of Organizational Economics, pp. 1014-1065.

Moen, E. R., AND A. Rosen (2013): "On-the-job search and moral hazard," Journal of the European Economic Association, 11(6), 1404-1431.

Murphy, K. J., AND J. ZABOJnik (2004): "CEO pay and appointments: A market-based explanation for recent trends," American Economic Review, pp. 192-196.

Neumark, D., D. Polsky, And D. Hansen (1999): "Has Job Stability Declined Yet? New Evidence for the 1990s," Journal of Labor Economics, 17(4), S29-64.

Postel-Vinay, F., AND J.-M. Robin (2004): "To match or not to match?: Optimal wage policy with endogenous worker search intensity," Review of Economic Dynamics, 7(2), 297-330.

Radner, R. (1985): "Repeated Principal-Agent Games with Discounting," Econometrica, 53(5), $1173-1198$.

Shapiro, C., AND J. E. Stiglitz (1984): "Equilibrium Unemployment as a Worker Discipline Device," American Economic Review, 74(3), 433-444.

Stevenson, B. (2009): "The Internet and Job Search," in Studies of Labor Market Intermediation, pp. 67-86. University of Chicago Press. 
Stewart, J. (2002): Recent trends in job stability and job security: Evidence from the March CPS. US Department of Labor, Bureau of Labor Statistics, Office of Employment and Unemployment Statistics.

Topel, R. H., AND M. P. Ward (1992): "Job Mobility and the Careers of Young Men," The Quarterly Journal of Economics, 107(2), 439-79.

Yamaguchi, S. (2010): "Job search, bargaining, and wage dynamics," Journal of Labor Economics, 28(3), 595-631. 


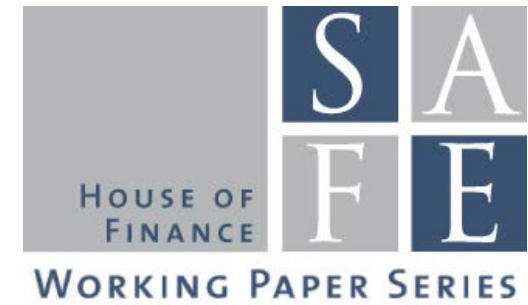

\section{Recent Issues}

No. 63 Nicola Fuchs-Schündeln, Michael Haliassos

No. 62 Patrick Behr, Alejandro H. Drexler, Reint Gropp, Andre Guettler

No. 61 Iñaki Aldasoro, Mike Seiferling

No. 60 Stefano Colonnello, Giuliano Curatola, Ngoc Giang Hoang

No. 59 Daniel Harenberg, Alexander Ludwig

No. 58 Michael Haliassos, Thomas Jansson, Yigitcan Karabulut

No. 57 Brigitte Haar

No. 56 Giuliano Curatola, Michael Donadelli, Alessandro Gioffré, Patrick Grüning

No. 55 Jan Pieter Krahnen, Peter Ockenfels, Christian Wilde

No. 54 Sascha Baghestanian, Todd B. Walker

No. 53 Holger Kraft, Claus Munk, Frank Thomas Seifried, Morgens Steffensen

No. 52 Holger Kraft, Thomas Seiferling, Frank Thomas Seifried

No. 51 Yacine Aït-Sahalia, Roger J. A. Laeven, Loriana Pelizzon
Does Product Familiarity Matter for Participation?

Financial Incentives and Loan Officers Behavior: Multitasking and Allocation of Effort Under an Incomplete Contract

Vertical Fiscal Imbalances and the Accumulation of Government Debt

Executive Compensation Structure and Credit Spreads

Social Security and the Interactions Between Aggregate and Idiosyncratic Risk

Incompatible European Partners? Cultural Predispositions and Household Financial Behavior

Financial Regulation in the EU - Cross-Border Capital Flows, Systemic Risk and the European Banking Union as Reference Points for EU Financial Market Integration

Austerity, Fiscal Uncertainty, and Economic Growth

Measuring Ambiguity Aversion: A Systematic Experimental Approach

Thar She Blows Again: Reducing Anchoring Rekindles Bubbles

Consumption and Wage Humps in a Life-Cycle Model with Education

Asset Pricing and Consumption-Portfolio Choice with Recursive Utility and Unspanned Risk

Mutual Excitation in Eurozone Sovereign CDS 